\title{
QRFP and Its Receptors Regulate Locomotor Activity and Sleep in Zebrafish
}

\author{
(DAudrey Chen, ${ }^{1 \star}$ Cindy N. Chiu, ${ }^{1 \star}$ Eric A. Mosser, ${ }^{1}$ Sohini Khan, ${ }^{1}$ Rory Spence, ${ }^{2}$ and David A. Prober ${ }^{1}$ \\ ${ }^{1}$ Division of Biology and Biological Engineering, California Institute of Technology, Pasadena, California 91125, and ${ }^{2}$ Keck Science Department, Claremont \\ McKenna, Pitzer and Scripps Colleges, Claremont, California 91711
}

The hypothalamus plays an important role in regulating sleep, but few hypothalamic sleep-promoting signaling pathways have been identified. Here we demonstrate a role for the neuropeptide QRFP (also known as P518 and 26RFa) and its receptors in regulating sleep in zebrafish, a diurnal vertebrate. We show that QRFP is expressed in $\sim 10$ hypothalamic neurons in zebrafish larvae, which project to the hypothalamus, hindbrain, and spinal cord, including regions that express the two zebrafish QRFP receptor paralogs. We find that the overexpression of QRFP inhibits locomotor activity during the day, whereas mutation of qrfp or its receptors results in increased locomotor activity and decreased sleep during the day. Despite the restriction of these phenotypes to the day, the circadian clock does not regulate qrfp expression, and entrained circadian rhythms are not required for QRFP-induced rest. Instead, we find that QRFP overexpression decreases locomotor activity largely in a light-specific manner. Our results suggest that QRFP signaling plays an important role in promoting sleep and may underlie some aspects of hypothalamic sleep control.

Key words: 26RFa; Gpr103; P518; QRFP; sleep; zebrafish

\section{Significance Statement}

The hypothalamus is thought to play a key role in regulating sleep in vertebrate animals, but few sleep-promoting signaling pathways that function in the hypothalamus have been identified. Here we use the zebrafish, a diurnal vertebrate, to functionally and anatomically characterize the neuropeptide QRFP. We show that QRFP is exclusively expressed in a small number of neurons in the larval zebrafish hypothalamus that project widely in the brain. We also show that QRFP overexpression reduces locomotor activity, whereas animals that lack QRFP signaling are more active and sleep less. These results suggest that QRFP signaling participates in the hypothalamic regulation of sleep.

\section{Introduction}

Sleep is an evolutionarily conserved behavior whose regulation is poorly understood. The hypothalamus is thought to play a key role in regulating sleep (for review, see Saper et al., 2010; Brown et al., 2012), in part due to the production of specific neuropeptides. For example, the neuropeptide hypocretin/orexin is produced in the hypothalamus of vertebrate animals, including zebrafish (de Lecea et al., 1998; Kaslin et al., 2004), and has a conserved role in

Received July 7, 2015; revised Nov. 13, 2015; accepted Dec. 12, 2015.

Author contributions: A.C., C.N.C., and D.A.P. designed research; A.C., C.N.C., E.A.M., S.K., R.S., and D.A.P. performed research; A.C., C.N.C., E.A.M., and D.A.P. analyzed data; A.C., C.N.C., and D.A.P. wrote the paper.

This work was supported by grants from the National Institutes of Health (NS-060996, NS-070911, and DA031367), the Mallinckrodt Foundation, the Rita Allen Foundation, and the Brain and Behavior Research Foundation to D.A.P. We thank Alex Mack Cruz, Axel Dominguez, and Kenna Molinder for animal husbandry assistance; Viveca Sapin, Brett Niles, and Jae Chu for technical assistance; and Andres Collazo for imaging assistance.

${ }^{*}$ A.C. and C.N.C. contributed equally to this work.

The authors declare no competing financial interests.

Correspondence should be addressed to David A. Prober, Division of Biology and Biological Engineering, California Institute of Technology, Pasadena, CA 91125. E-mail: dprober@caltech.edu.

DOI:10.1523/JNEUROSCI.2579-15.2016

Copyright $\odot 2016$ the authors $\quad 0270-6474 / 16 / 361823-18 \$ 15.00 / 0$ promoting wakefulness (Chemelli et al., 1999; Lin et al., 1999; Peyron et al., 2000; Prober et al., 2006; Adamantidis et al., 2007; Yokogawa et al., 2007; Elbaz et al., 2012). Conversely, the hypothalamic neuropeptide melanin-concentrating hormone, and the neurons that produce it, has been shown to promote sleep in nocturnal rodents (Verret et al., 2003; Willie et al., 2008; Konadhode et al., 2013; Tsunematsu et al., 2014). The hypothalamus produces many other neuropeptides (van den Pol, 2012), but their requirement for normal sleep/wake behaviors is largely unexplored, especially in diurnal animals.

A family of hypothalamic neuropeptides containing a C-terminal Arg-Phe- $\mathrm{NH}_{2}$ motif has been described in several vertebrate and invertebrate animals, and these peptides are implicated in regulating a variety of physiological and behavioral processes (Sandvik et al., 2014). QRFP (also known as P518 and $26 \mathrm{RFa}$ ), the most recently identified vertebrate member of this family, has been shown to affect feeding, locomotor activity, energy homeostasis, reproduction, bone formation, and nociception in mammals (Chartrel et al., 2011; Ukena et al., 2014). However, these findings are largely based on the injection of 


\section{A 26RFa_Hs TSGPLGNLAEELNGYSRKKGGFSFRF 26RFa_Dr RNEALTSI A GGLQAFNRQKGGFGFRF}

B QRFP_Hs QRFP_Mm QRFP_Ca QRFP_Dr QRFP_Dr i

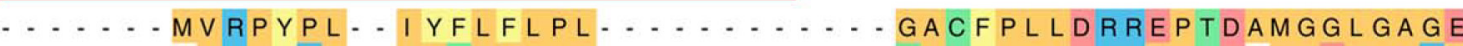
MRGFRP - L L L SLLLPL ........... SACFPLLDRRGPTD - I GDIGARM MKFQVI HLSSTLQTTILFLLVLLVQPPRGLMLPHHPMVYLPMLDNPEWEAALLQLQASL $M K I Q V F H L S S T L Q T T V F F L L V L L V H P P R S L M L P H Q P M V Y L P R L Y N P E W E A A M L R L Q A S L$

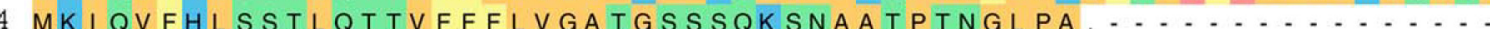

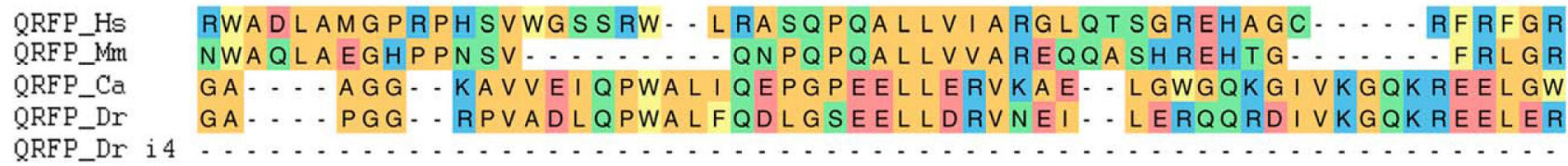

RWA DLAMGPRPHSVWGSSRW- - LRASQPQALLVIARGLQTSGREHAGC - - - RFRFGR

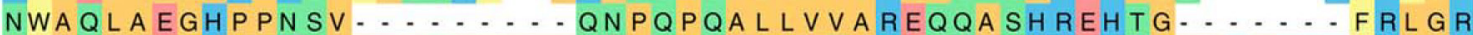
GA - . - AGG - KA V VEIQPWA LIQEPGPEELLERVKAE - LGWGQKG।VKGQKREELGW GA - - P PGG - RPVADLQPWALFQDLGSEELLDRVNEI - LERQQRDIVKGQKREELER

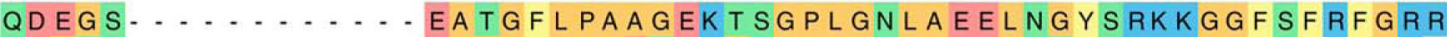

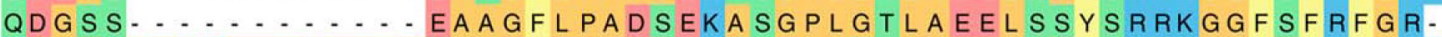
KPMGTFPDNLIVDVPYPQGGEVEEEGGEKQNEALTSIAGGLQAFNRQKGGFGFRFGKK RPMGTFPDNHIMPLLYPQGGEAEEVGGEKRNEALTSIAGGLQAFNRQKGGFGFRFGRK

Figure 1. Conservation of QRFP protein sequence in mammals and fish. $\boldsymbol{A}$, Amino acid sequences of the known human and predicted zebrafish $26 \mathrm{RF}$ a mature peptides. Boxed region at $\mathrm{C}$ termin indicates heptapeptide sequence that is critical for biological activity. $\boldsymbol{B}$, Alignment of QRFP protein sequences from human (Hs, ENSG00000188710), mouse (Mm, ENSMUSG00000043102), goldfish (Ca, uniprot ID B6ECY8), zebrafish wild-type (Dr, ENSDARG00000094637), and zebrafish 4 bp insertion mutant (Dr i4). Zebrafish QRFP predicted signal sequence is indicated by a red line. Human 26RFa and 43RFa peptides are indicated by gray and black lines, respectively. Amino acids are colored to indicate residues with similar properties. The coding sequence of the zebrafish mutant terminates just after the predicted signal sequence but before the predicted mature peptide domain, and is thus likely to be nonfunctional.
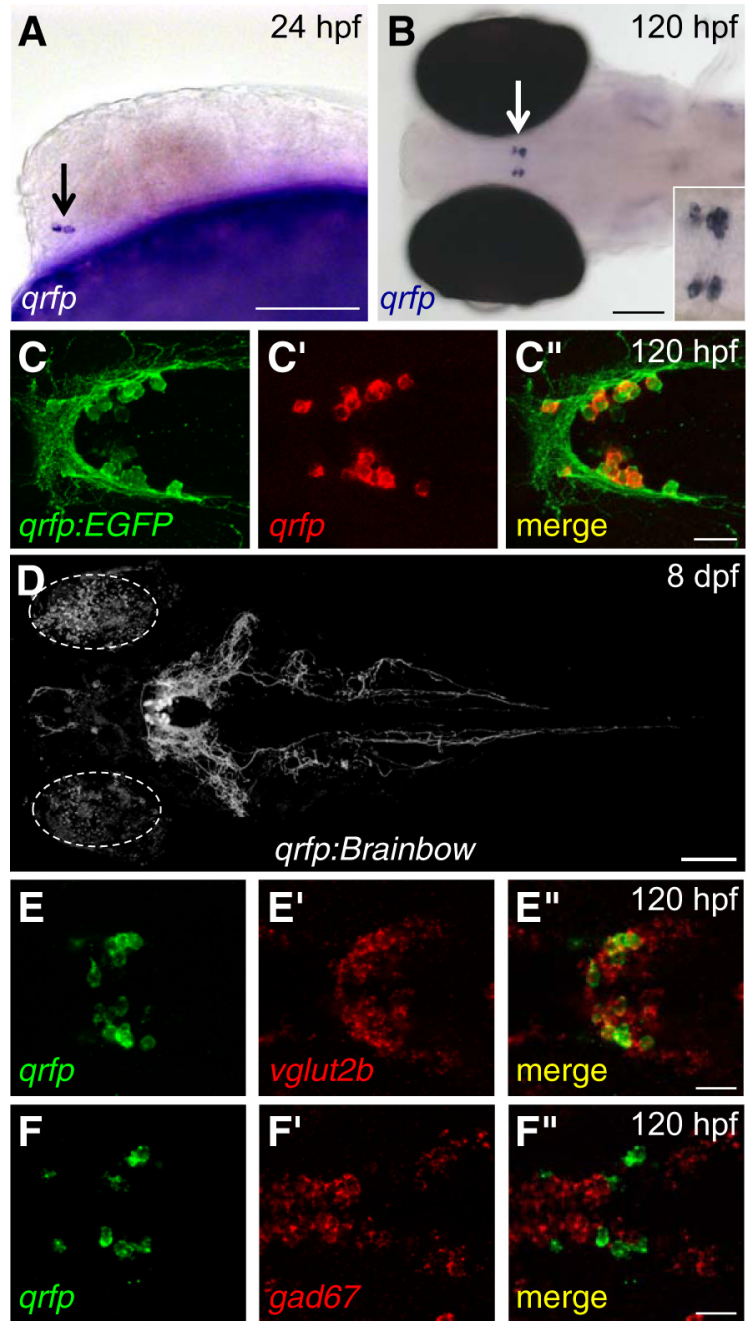

QRFP peptides into rodent brains and may not reflect the normal function of endogenous QRFP. One of the two identified murine QRFP receptors (gpr103a) has been knocked out in mice (Baribault et al., 2006). These mutants exhibit defects in bone formation but lack obvious additional phenotypes. This result suggests either that endogenous QRFP signaling is not required for other behavioral and physiological processes that are affected by QRFP peptide injection, or that other proteins function redundantly with Gpr103a. However, animals lacking qrfp or the second murine $q r f p$ receptor paralog ( $g p r 103 b)$ have not been reported in any animal model. Zebrafish QRFP (Liu et al., 2009, 2015; Chen et al., 2013; Ukena et al., 2014) and Gpr103 (Chen et al., 2013; Larhammar et al., 2014; Ukena et al., 2014) orthologs have been identified, but have not been functionally characterized. Here we describe the zebrafish qrfp and gpr103 orthologs, characterize qrfp- and gpr103-expressing neurons, and show that QRFP and its receptors regulate locomotor activity and sleep in zebrafish larvae.

\section{Materials and Methods \\ Zebrafish genetics}

Zebrafish were raised on a $14 \mathrm{~h} / 10 \mathrm{~h}$ light/dark cycle at $28.5^{\circ} \mathrm{C}$, with lights on at 9:00 A.M. and off at 11:00 P.M. Wild-type (WT), transgenic, and mutant stocks come from a background of TL $\times$ AB WT strains. All experiments were performed using standard protocols (Westerfield,

$\leftarrow$

Figure 2. QRFP is expressed in glutamatergic hypothalamic neurons. $\boldsymbol{A}, \boldsymbol{B}, \mathrm{ISH}$ shows that qrfp is expressed in the hypothalamus in two to four neurons at $24 \mathrm{hpf}(\boldsymbol{A})$ and $10-15$ neurons at $120 \mathrm{hpf}$ ( $\boldsymbol{B}$, enlarged in inset). $\boldsymbol{C}$, EGFP in $\operatorname{Tg}($ grfp:EGFP) larvae is specifically observed in qrfp-expressing neurons. D, An $8 \mathrm{dpf} T$ Tgrfp:Brainbow) larva that did not undergo (remediated recombination, and thus expresses tdTomato, is shown. grfp-expressing neurons project widely in the hypothalamus and hindbrain, sparsely to the forebrain, and down the spinal cord (see also Movie 1). Circles indicate autofluorescence in the eyes. $\boldsymbol{E}, \boldsymbol{F}$, Double-FISH at $120 \mathrm{hpf}$ shows that grfp-expressing neurons express vglut $2 b(\boldsymbol{E})$ but not gad67 $(\boldsymbol{F})$. Images are single confocal sections $(\boldsymbol{E}, \boldsymbol{F})$ or maximum intensity projections $(\boldsymbol{C}, \boldsymbol{D})$. Rostral is to the left for all images. Side $(\boldsymbol{A})$ and dorsal $(\boldsymbol{B}-\boldsymbol{F})$ views are shown. Scale bars: $\boldsymbol{A}, \boldsymbol{B}, \boldsymbol{D}, 100 \mu \mathrm{m} ; \boldsymbol{C}, \boldsymbol{E}, \boldsymbol{F}, 20 \mu \mathrm{m}$. 


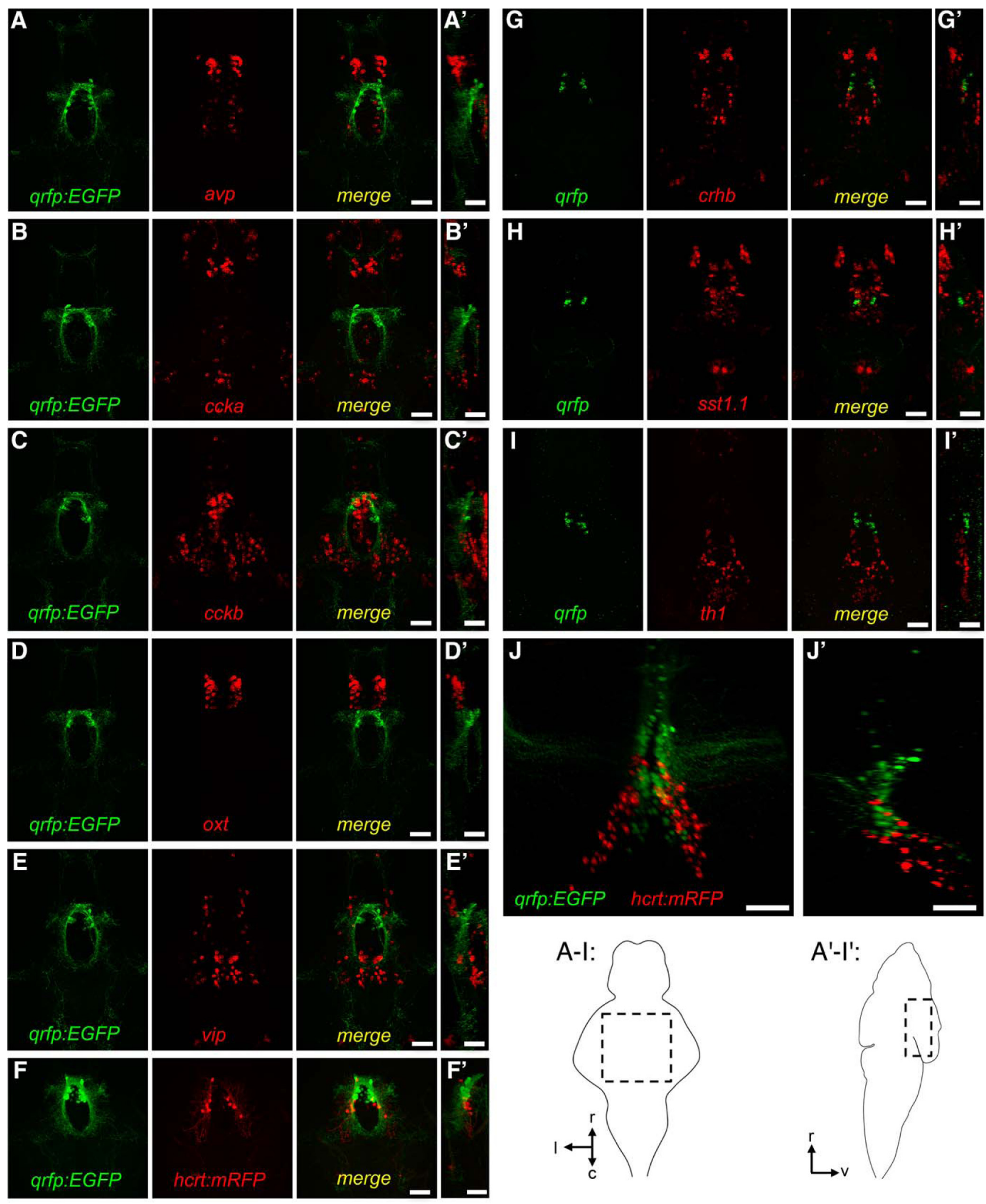

Figure 3. Hypothalamic grfp expression does not colocalize with other hypothalamic markers. $A-E, G-I$, Images show immunohistochemistry using a GFP-specific antibody for Tg(qrfp:EGFP) larvae (green, $\boldsymbol{A}-\boldsymbol{E}$ ), or FISH using a qrfp-specific probe (green, $\mathbf{G}-\boldsymbol{I})$, and FISH using probes specific for other hypothalamic markers (red), including avp (A), ccka (B), cckb (C), oxt (D), vip (E), crhb

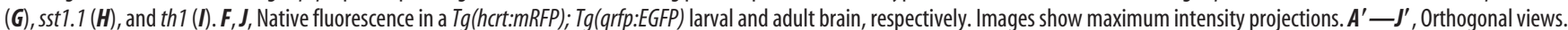
Schematic diagrams indicate larval brain regions shown in panels $\boldsymbol{A}-\boldsymbol{I}$ and $\boldsymbol{A}^{\prime} \boldsymbol{-} \boldsymbol{I}$, and indicate rostral, caudal, lateral, and ventral axes. Brains from $120 \mathrm{hpf}$ larvae $(\boldsymbol{A}-\boldsymbol{I})$ and a 22 -month-old adult (J) are shown. Scale bars: $A-I, 50 \mu \mathrm{m} ; J, 100 \mu \mathrm{m}$. 


\section{A}

Gpr103 Hs Gpr103ā_Mm Gpr103b_Mm Gpr103a Dr Gpr103a Dr Gpr103b_Dr Gpr103b Dr
M- QALN I TPEQFSRLLRDHNLTREQFIALYRLRPLVYTPELPGRAKLALVLTGVLIFALALFGNALVFYVVTRS $M-Q A L N I T A E Q F S R L L S A H N L T R E Q F I H R Y G L R P L V Y T P E L P A R A K L A F A L A G A L I F A L A L F G N S L V I Y V V T R S$ M.- SWNLTAEQLSALLRLHNLTRAQFIAHYGLRPLVLTPQLPARARLALLLVGMLIFALALFGNALVVYVVTRS M - GDKKI TPEVLEQLLQFYNLTRQEFIETYQIEPLVYIPELPAGAKTTFVIVYTVIFLLALVGNSVVVYIVLRK 11 M - GDKKI TPEVLEQLQSYPSGVHRD............ VPDRAAG

MTATTKI TPEVLQELLQYYNLSRQEFIDTYNIQPLVYIPELPAGVKSTFVVMYVIIFVLALVGNSLVVYVVVRK MTATTKITPEVLQELLQYYNLSRQEFIDTYNIQPLVYIPELPAGVKSTFVVMYVIIFVLALVGNSLVVYVVVRK
Gpr103 Hs Gpr103ā Mm Gpr103b_Mm Gpr103a Dr Gpr103a Dr Gpr103b_Dr Gpr103b Dr

Gpr103_Hs Gpr103a_Mm Gpr103b Mm Gpr103a-Dr Gpr103a_Dr Gpr103b Dr Gpr103b_Dr

Gpr103_Hs Gpr103ā Mm Gpr103b_Mm Gpr103a_Dr Gpr103a_Dr Gpr103b_Dr Gpr103b Dr d

KAMRTVTNIFICSLALSDLLITFFCI PVTMLQN I SDNWLG.

KAMRTVTNIFICSLALSDLLIAFFCI PVTMLQN I SDKWLG

GAF I CKMVPFVQSTAVVTEILTMTCI AVERH RGIQTATNIFICSLAVSDLLISFFCIPFTLLQN ISSEWFG GVLVCKTVPFVQTTAVVTGILTMTCI AVERY RA I RTATNIFICSLAVSDLLITFFCI PFTLLQNISSEWLGVHTGVLVCKTVPFVQTTAIVTGILTMTCIAIERY d4 RAIRTATNIFICSLAVSDLLITFFCIPFTLLQNISSEWLGVHTGVLVCKTVPFVQTTAIVTGILTMTCIAIERY

QGLVHPFKMKWQYTNRRAFTMLGVVWLVAVIVGSPMWHVQQLEI KYDFLYEKEHICCLEEWTSPVHQKIYTTFI QGL I HPFKMKWQYTTRRAFT I LGVVWLAA I IVGSPMWHVQRLEIKYDFLYEKEHVCCLEEWASPMHQRIYTTF। QGLVHPFKMKRQYTNQRAFTMLGVVWLVA I I I GSPMWHVQRLEIKYDFLYEKEHICCLEEWSSPVHQKI YTTF। QGIVHPLKIKRQCTPQRA YRMLGVVWIAAMMVGSPMLFVQQLEVKYDFLYDNHHVCCQERWRSSAHRKRYATFI

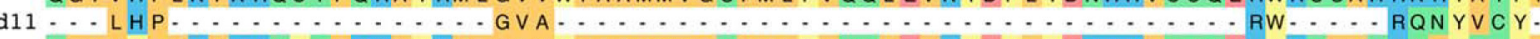
QGIVYPLKMKRQYTPKRAYRMLGLVWIAAVMVGSPMLFVQQLEVKYDFLYDHHHVCCQERWHSLLQRQLYTTFI d4 QGIVYPLKMKRQYTPKRAYRMLGLVWIAAVMVGSPMLFVQQLEVKYDFLYDHHHVCCQERWHSLLQRQLYTT.

LVILFLLPLMVMLILYSKIGYELWIKKRVGDGSVLRTIHGKEMSKIARKKKRAVIMMVTVVALFAVCWAPFHVV LVILFLLPLVVMLVLYSKIGYELWIKKRVGDSSALQTIHGKEMSKIARKKKRAVVMMVTVVALFAACWAPFHVV LVTLFLLPLLLLSVLYGKIGYELWIKKRIGDGSVLRTIHGKEMFKIARKKKRAVIMMVTVVVLFAVCWAPFHIV LVFLFLLPLAAMLILYTRIGIELWI RKQVGDSSVLNAMNQREVSKIARKKRRAIKMMVTIVVLFTVCWAPFHTV

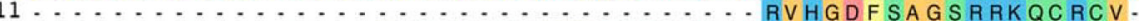
MVALFLLPLAAMLFLYSRIGVELWIRKRVGDASVLSTMNHREISKISRKKKRAVKMMITIVLLFTVCWAPFHIV

Gpr103_Hs Gpr103a_Mm Gpr103b_Mm Gpr103a Dr Gpr103a_Dr d11 Gpr103b Dr Gpr103b Dr d4 Gpr103_Hs Gpr103b Mm Gpr103a_Dr Gpr103a_Dr d11. Gpr103b Dr Gpr103b Dr d4

B

HMMI EYSNFEKEYDDVT I KMI FA IVQI IGFSNSICNPIVYAFMNENFKKNVLSAVCYCIVNKTFSPAQRHGNSG HMMVEYSNFEKEYDDVTIKMVFAVAQTIGFFNSICNPFVYAFMNENFKKNFLSAVCYCIVRETFSPGQKPGNSG HMM I EYSNFEKEYDEVTIKMIFA IVQI I GFFNSICNPI I YALMNENFKKNFVSAVCYCIVKETPSSARKHGSSG HILFEYSYLNKKYDDVTVNMI I AVAQA I GFSNSFNNPI I YAFMNENFQKNCMSTLSVCIRRSSHRVDVKDKSKV HMLFEYNDLEKKYNEVTVNMI I AVVQA I GFSNSFNNPIVYAFMNENFKKSCLSTLSSYLRRPVQRQSVPRQNLSV 4

I TMMRKKAK- FSLRENPVEETKGEAFSDGN I EVKLCEQTEE. KKKLKRHLALFRSELAENSPLDSGH. . . . I SMMQKRAK - LSRSQRPVAEAKGDLFSDANVDVKLCEQPGE-KRQLKRQLAFFSSELSENSTFGSGHEL- - .

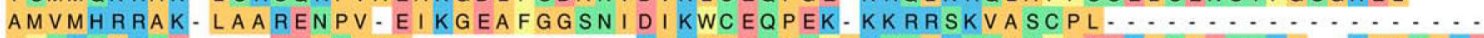
LFCKSARQD.... EEI SVMP............ RI HI I DQVQYARSNMRTSMSFLEERMSVENNRM - HAGCIRD

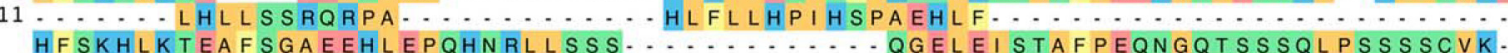

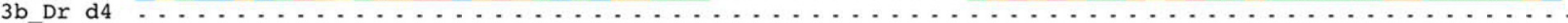

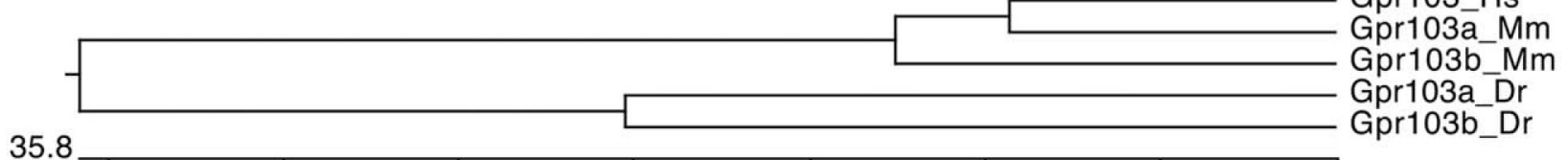

35

30

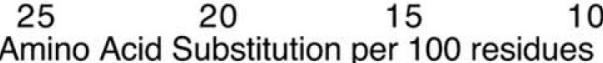

Figure 4. Conservation of Gr103 protein sequence in mammals and fish. A, Alignment of Gpr103 protein sequences from human (Hs, ENSG00000186867), mouse (Mm: Gpr103a, ENSMUSG00000058400; Gpr103b, ENSMUSG00000029917), and zebrafish (Dr: Gpr103a, ENSDARG00000039349; Gpr103b, ENSDARG00000068422), including the zebrafish Gpr103a 11 aa deletion mutant ( $\mathrm{d} 11$ ) and Gr103b 4 aa deletion mutant (d4). Predicted transmembrane domains are indicated by gray lines. The coding sequences of the zebrafish Gpr103a and Gpr103b mutants undergo frameshifts before the first and fifth predicted transmembrane domains, respectively, and thus are likely to be completely nonfunctional. $\boldsymbol{B}$, Phylogenetic tree of human, mouse, and zebrafish $\mathrm{Gpr} 103$ receptors.

2000) in accordance with the California Institute of Technology Institutional Animal Care and Use Committee guidelines. Zebrafish mutants were generated using zinc finger nucleases (ZFNs) and TAL effector nucleases (TALENs), as described previously (Chen et al., 2013).

qrfp (ZFIN gene name si:ch211-185o22.2) mutant. ZFN binding sites were $5^{\prime}$-ACAGTCTTC- $3^{\prime}$ and $5^{\prime}$-AGCACCAAC- $3^{\prime}$. qrfp mutant line i4 contains a 4 bp insertion (TTCT, after nucleotide 51 of the open reading frame). The mutation results in a change in reading frame after amino acid (aa) 18 and a premature stop codon after aa 42, compared with 168 aa for the WT protein. qrfp mutants were genotyped using the primers $5^{\prime}$ -
AATGGTCAGTTCAGGGTGATG-3' 5' $^{\prime}$-CAGACCACAGTCTTCttctTTC TT- $3^{\prime}$, and $5^{\prime}$-ATTGCTGCTTCCCATTCAG- $3^{\prime}$. These primers produce a 212 bp band for homozygous WT; 216 and 123 bp bands for homozygous mutant; and 212, 216, and 123 bp bands for heterozygous mutant. These bands were resolved on a $4 \%$ agarose gel. For qrfp mutant behavioral experiments, we mated $q r f p^{-1-}$ to $q r f p^{+/-}$fish and compared $q r f p^{-1-}$ larvae to their $q_{r f p}+1-$ siblings.

gpr103a (ZFIN gene name qrfpra) mutant. TALEN binding sites were 5'-TCCTGAAGTGCTGGAGCA-3' and 5'-TCCTGACGGGTAAGATT- ${ }^{\prime}$. gpr103a mutant d 11 contains an 11 bp deletion (TGCAGTTTTAC, after nucle- 


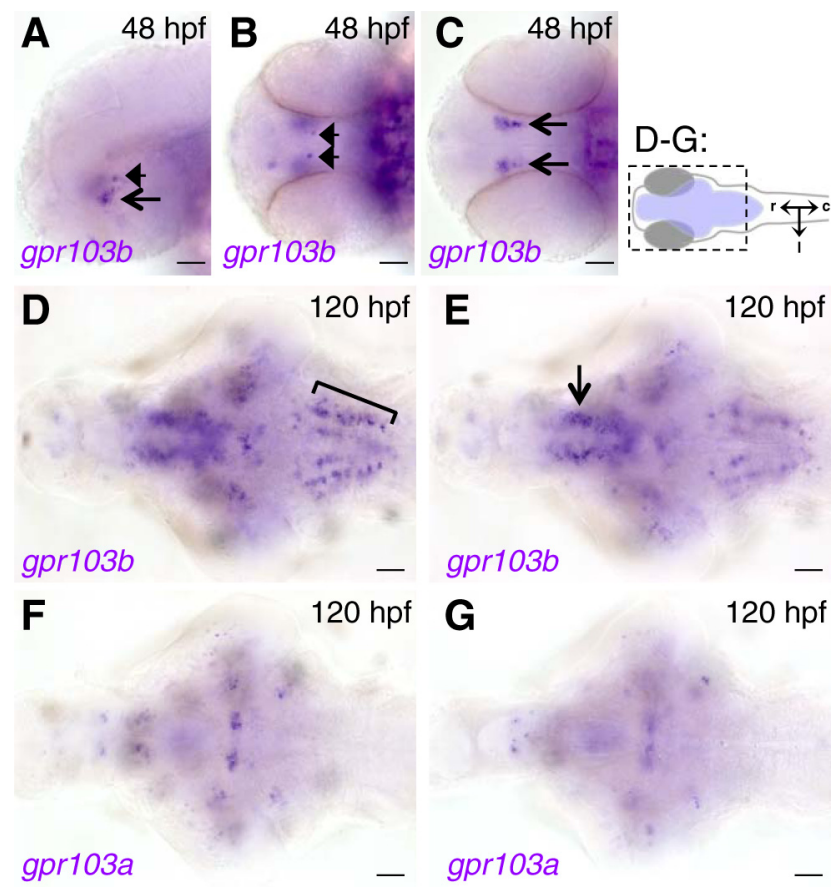

Figure 5. gpr103a and gpr103b are expressed in distinct populations in the larval zebrafish brain. A-C, gpr103b expression is first observed in bilaterally symmetric populations of 1-2 neurons in the dorsal hypothalamus (arrowheads) and 5-10 neurons in the ventral hypothalamus (arrows) at $48 \mathrm{hpf}$. D, E, At $120 \mathrm{hpf}$, expression is observed in rostral-caudal stripes in the hindbrain (bracket, $\boldsymbol{D}$ ) and in a large hypothalamic domain (arrow, $\boldsymbol{E}$ ), in addition to several small nuclei in the hypothalamus, midbrain, and hindbrain. gpr103a expression is not observed at $48 \mathrm{hpf}$ (data not shown), but is expressed in several small bilaterally symmetric nuclei in the forebrain, hypothalamus, midbrain, and hindbrain at $120 \mathrm{hpf}(\boldsymbol{F}, \boldsymbol{G})$. Schematic diagram in top right indicates the region shown in $D-G$, with the brain shaded blue, and indicates rostral, caudal, and lateral axes. Images shown in $\boldsymbol{D}$ and $\boldsymbol{F}$ are dorsal to those shown in $\boldsymbol{E}$ and $\boldsymbol{G}$. Side $(\boldsymbol{A})$, ventral $(\boldsymbol{B}, \boldsymbol{C})$, and dorsal $(\boldsymbol{D}-\boldsymbol{G})$ views are shown. Scale bars, $50 \mu \mathrm{m}$.

otide 43 of the open reading frame). The mutation results in a change in reading frame after aa 14 and a premature stop codon after aa 105, compared with 355 aa for the WT protein. gpr103a mutants were genotyped using the primers $5^{\prime}$ CAGCCGATGTGTCAGAAGAA- $3^{\prime}$ and $5^{\prime}$-CGAGAGCCAGCAGAAAAA TC- $3^{\prime}$, followed by digestion with PstI (New England BioLabs), which cuts the $320 \mathrm{bp}$ WT PCR product into 185 and $135 \mathrm{bp}$.

gpr103b (ZFIN gene name qrfprb) mutant. ZFN binding sites were $5^{\prime}-$ ACCACCTTC-3' and 5' -AGCGCCACC-3' ${ }^{\prime}$.gpr $103 b$ mutant d 4 contains a 4 bp deletion (TCAT, after nucleotide 661 of the open reading frame). The mutation results in a change in reading frame and a premature stop codon after aa 220, compared with 429 aa for the WT protein. gpr103b mutants were genotyped using the primers $5^{\prime}$-TGGCAGAGCTGCGATAAAAA-3' and 5'-TGGG GAAATGAGGGATAACTGA-3', followed by digestion with XcmI (New England BioLabs), which cuts the $480 \mathrm{bp}$ WT PCR product into 220 and $260 \mathrm{bp}$. For behavioral experiments, to assay a sufficient number of $g p 103 a^{-1-} ; g p r$ $103^{-1-}$ larvae to generate robust data, we incrossed $g p^{2} 103 a^{+1-} ; g p^{\prime} 103^{+1-}$

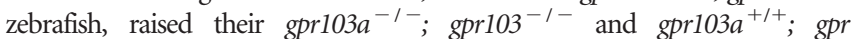
$103^{+/+}$progeny to adulthood, and then compared larvae obtained from a gpr103a $a^{-1-}$; gpr103 $3^{-1-}$ incross to those obtained from a $g$ pr103a $a^{+/+}$; gpr103 $^{+/+}$incross.

$\operatorname{Tg}$ (qrfp:EGFP) and $\operatorname{Tg}(q r f p: B r a i n b o w)$. A $1 \mathrm{~kb}$ region of genomic DNA immediately $5^{\prime}$ to the $q r f p$ start codon was amplified from genomic zebrafish DNA using the primers 5'-CTGACTCTCCCATCAGTCCT-3' and 5'-CTGAAATTTAAGGAATAATTTAAAGTTG-3', and subcloned upstream of enhanced green fluorescent protein (EGFP) or a Brainbow transgene containing tdTomato, mCerulean, and enhanced yellow fluorescent protein (Pan et al., 2013) in a vector containing flanking Tol2 transposase recognition sequences. Stable transgenic lines were generated using the Tol2 transposase method (Asakawa and Kawakami, 2009). The image shown in Figure $2 D$ is a $T g$ (qrfp:Brainbow) larva in which no recombination had been induced, and thus only tdTomato is expressed. This image stack was obtained using a two-photon microscope with avalanche photodiode detectors (710 LSM, Zeiss).

$T g(h s p: Q R F P)$. Full-length zebrafish qrfp cDNA was isolated using 5' and 3' rapid amplification of cDNA ends (RACE; FirstChoice RLMRACE, Ambion), and the qrfp open reading frame was cloned downstream of the zebrafish $h s p 70 c$ promoter (Halloran et al., 2000) using the primers $5^{\prime}$-ATGAAAATCCAGGTTTTTCATC- ${ }^{\prime}$ ' and $5^{\prime}$-TTACTTCCT GCCAAATCGAA- $3^{\prime}$ in a vector containing flanking ISceI meganuclease sites. Stable transgenic fish were generated using the ISceI method (Thermes et al., 2002). For behavioral experiments, we mated $T g$ (hsp: QRFP)/+ zebrafish to WT, and compared $\operatorname{Tg}(h s p: Q R F P) /+$ larvae to their WT siblings.

\section{In situ hybridization}

Samples were fixed in $4 \%$ paraformaldehyde (PFA)/PBS for $12-16 \mathrm{~h}$ at room temperature. In situ hybridization (ISH) was performed using digoxygenin (DIG)-labeled antisense riboprobes (DIG RNA Labeling Kit, Roche), as previously described (Thisse and Thisse, 2008). Doublefluorescent in situ hybridization (FISH) was performed using DIG- and 2,4-dinitrophenol (DNP)-labeled riboprobes, and the TSA Plus DNP System (PerkinElmer). Probes specific for arginine vasopressin (avp; Eaton et al., 2008); oxytocin (oxt; Unger and Glasgow, 2003); tyrosine hydroxylase 1 (th1; Guo et al., 1999); vasoactive intestinal polypeptide (vip; Wolf and Ryu, 2013); and glutamate decarboxylase 65 (gad65), gad67, vesicular glutamate transporter 1 (vglut1), vglut2a, and vglut2b (Higashijima et al., 2004) have been described. Plasmids containing qrfp (GenBank clone CR927915, $531 \mathrm{bp}$ ) and corticotropin releasing hormone $b$ (crhb) (GenBank clone CK352624, 849 bp) expressed sequence tags were used for riboprobe synthesis. PCR products generated from larval zebrafish cDNA were used as templates for riboprobe synthesis using the following primers: cholecystokinin a (ccka), 5'-TCTCTCCCTCGTTCCT CAGA- $3^{\prime}$ and $5^{\prime}$-TAATACGACTCACTATAGGGGTAGACGAGGAGCCG CATT-3' (452 bp); cckb, 5' -CTCTCTCTGCGTCTCTGCAA-3' and 5'TAATACGACTCACTATAGGGTTATTCATAGACACCTGTGATATGT CG-3' (690 bp); gpr103a, 5' -TGAAGTGCTGGAGCAACTACTG-3' and 5' -TAATACGACTCACTATAGGGAAACAGCACGACAATGGTGA-3' (823 bp); gpr103b, 5' - GGAACTCCTGCAGTACTATAACCTC-3' and 5' -TAATACGACTCACTATAGGGATGGTGTCTGAAGTGGCACA-3' (1327 bp); and somatostatin 1.1 (sst1.1), 5' -TCGTTTAAAAG GCAACTTTGG-3' and 5'-TAATACGACTCACTATAGGGACAATTA AAAGCAGATTTGCACAC-3' (670 bp). FISH of Tg(qrfp:EGFP) larvae used DIG-labeled riboprobes followed by immunohistochemistry with a rabbit anti-GFP primary antibody (MBL International) and an Alexa Fluor 488 anti-rabbit secondary antibody (Life Technologies). Samples were mounted in 50\% glycerol/PBS and imaged using a compound microscope (Axioimager, Zeiss) or confocal microscope (780 LSM, Zeiss).

\section{Passive clarity technique}

Passive clarity technique (PACT) clearing was performed as described previously (Yang et al., 2014). Adult (22-month-old) Tg(qrfp:EGFP); $\mathrm{Tg}$ (hcrt:mRFP) zebrafish (Liu et al., 2015) were anesthetized in $0.2 \%$ tricaine, killed by incubation in ice water for $15 \mathrm{~min}$, and decapitated. Intact heads were fixed in $4 \% \mathrm{PFA} / \mathrm{PBS}$ overnight at $4^{\circ} \mathrm{C}$, then whole brains were dissected from their skulls and placed in A4P0 hydrogel monomer solution at $4^{\circ} \mathrm{C}$ overnight with agitation. Samples were then degassed with nitrogen for $5 \mathrm{~min}$ and incubated for $2-3 \mathrm{~h}$ at $37^{\circ} \mathrm{C}$ to allow for polymerization. Samples were rinsed in $0.1 \mathrm{M}$ PBS and excess polymerized gel was removed with a Kimwipe. Samples were then rinsed in 0.1 M PBS and placed in $8 \%$ SDS at $37^{\circ} \mathrm{C}$ with agitation for $48 \mathrm{~h}$ or until clearing was complete. Samples were then washed with $0.1 \mathrm{M}$ PBS and placed in Refractive Index Matching Solution (RIMS) with a refractive index of 1.42. Samples were mounted in 1.42 RIMS, and native fluorescence was imaged using a confocal microscope (780 LSM, PlanApochromat $10 \times / 0.45$ M27 objective, Zeiss). Image reconstructions were performed using Imaris (Bitplane).

\section{Behavioral analysis}

Larval zebrafish were placed into each well of a 96-well plate (7701-1651, Whatman) containing E3 embryo medium ( $5 \mathrm{~mm} \mathrm{NaCl}, 0.17 \mathrm{~mm} \mathrm{KCl}$, 
$0.33 \mathrm{~mm} \mathrm{CaCl}, 0.33 \mathrm{~mm} \mathrm{MgSO}_{4}, \mathrm{pH}$ 7.4; Prober et al., 2006). Plates were sealed with an optical adhesive film (4311971, Applied Biosystems) to prevent evaporation. The sealing process introduces air bubbles in some wells, which are discarded from analysis. Locomotor activity was monitored using an automated videotracking system (Viewpoint Life Sciences) with a Dinion one-third inch Monochrome camera (Dragonfly 2, Point Grey) fitted with a fixed-angle megapixel lens (M50 18-MP, Computar) and infrared filter. The movement of each larva was captured at $15 \mathrm{~Hz}$ and recorded using the quantization mode with 1 min integration time bins. The 96-well plate and camera were housed inside a custommodified Zebrabox (Viewpoint Life Sciences) that was continuously illuminated with infrared lights and with white lights from 9:00 A.M. to 11:00 P.M., unless noted otherwise. The 96well plate was housed in a chamber filled with recirculating water to maintain a constant temperature of $28.5^{\circ} \mathrm{C}$. Heat shocks (HSs) were performed by placing 96 -well plates in a $37^{\circ} \mathrm{C}$ water bath for $1 \mathrm{~h}$. The parameters used for detection were as follows: detection threshold, 15; burst, 29; freeze, 3 . For experiments that did not involve a heat shock and in which larvae were tested in $14 \mathrm{~h} / 10 \mathrm{~h}$ light/dark cycles, daytime averages were calculated from Days 5, 6, and 7 , and nighttime averages were calculated from Nights 5 and 6 . For larvae raised and tested in constant dark or constant light, data were averaged for $30 \mathrm{~h}$ before HS ( pre-HS) and $30 \mathrm{~h}$ after HS ( post-HS). Data were processed using custom PERL and Matlab (The MathWorks) scripts, and statistical tests were performed using Matlab and Prism (GraphPad).

\section{Statistical analysis}

In all statistical tests, the significance threshold was set to $p<0.05$. Parametric analyses were applied because data follow an approximately normal distribution. Asterisks in figures denote statistics for pairwise comparisons performed using an unpaired Student's $t$ test or Tukey's HSD test to correct for multiple comparisons where appropriate. Error bars indicate the SEM. To determine whether the observed changes in $T g(h s p: Q R F P)$ larval behavior are due to heat shock, WT and $\operatorname{Tg}$ (hsp: QRFP) locomotor activity pre-HS and post-HS was compared using two-way ANOVA.

\section{Quantitative RT-PCR}

Larval zebrafish were raised on a $14 \mathrm{~h} / 10 \mathrm{~h}$ light/dark cycle at $22^{\circ} \mathrm{C}$ with lights on at 9:00 A.M. and off at 11:00 P.M. At $6 \mathrm{~d}$ post-fertilization (dpf), individual larvae were placed into each well of 96-well plates (675075, Greiner) and placed into constant darkness starting at 6:00 P.M. After $24 \mathrm{~h}$ in the dark, total RNA was isolated using Trizol (15596-026, Life Technologies) from 24 pooled larvae every $6 \mathrm{~h}$ for $24 \mathrm{~h}$. cDNA was synthesized from $5 \mu \mathrm{g}$ of total RNA using Superscript III Reverse Transcriptase (18080-051, Invitrogen), and quantitative PCR was performed using SYBR green master mix (4364346, Life Technologies) in an ABI PRISM 7900HT (Life Technologies) instrument using the following primers: Perlb-F, 5'-ATCCAGACCCCAATACAAC-3'; Perlb-R: 5'GGGAGACTCTGCTCCTTCT-3'; QRFP-F: 5'-TGGATGTAGATCGCTGA TGG-3'; and QRFP-R: 5'-GGGAGGATGAACCAGTAGCA-3'. $\Delta$ Ct was calculated using ribosomal protein $l 13 a(r p l 13 a)$ as a reference gene, using the primers: Rpl13a F, 5' -TCTGGAGGACTGTAAGAGGTATGC-3'; and Rpl13a
R, 5'-AGACGCACAATCTTGAGAGCAG-3'. Relative expression levels were determined by using the $\Delta \Delta \mathrm{Ct}$ method (Livak and Schmittgen, 2001), normalized to the highest $\mathrm{Ct}$ value for each gene.

\section{Results}

The QRFP neuropeptide is conserved in zebrafish

The QRFP preproprotein is known or predicted to be cleaved into a 26 aa peptide (26RFa) in humans (Chartrel et al., 2003; Jiang et al., 2003), rodents (Chartrel et al., 2003; Jiang et al., 2003), frogs (Chartrel et al., 2003), and goldfish (Liu et al., 2009), and a 25 or 27 aa peptide in birds (Ukena et al., 2010; Tobari et al., 2011). The preproprotein is also cleaved into an N-terminal elongated peptide of 43 aa (43RFa) in mammals (Fukusumi et al., 2003; Takayasu et al., 2006), and a predicted 34 aa peptide in quail and chicken (Ukena et al., 2010). These peptides all contain a 


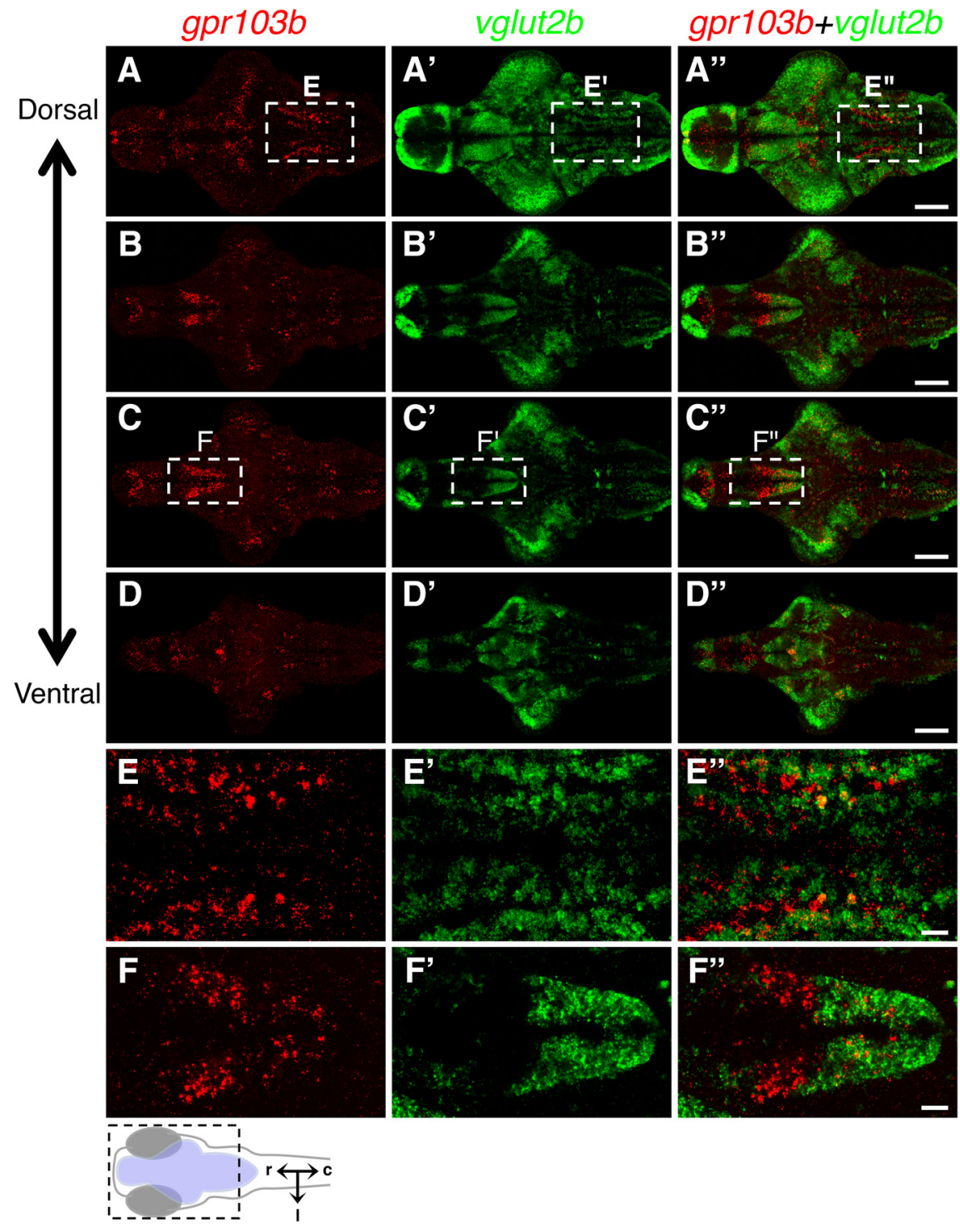

Figure 7. gpr103b is expressed in glutamatergic caudal hypothalamic neurons and not in glutamatergic hindbrain neuron stripes. Double-FISH using probes specific for gpr103b (red) and vglut2b (green) on $120 \mathrm{hpf} \mathrm{larval} \mathrm{brains} \mathrm{is} \mathrm{shown.} \boldsymbol{A}-\boldsymbol{D}$, The same brain imaged at different focal planes, moving from dorsal $(\boldsymbol{A})$ to ventral $(\boldsymbol{D})$. The boxed regions in $\boldsymbol{A}$ and $\boldsymbol{C}$ are shown at higher magnification in $\boldsymbol{E}$ and $\boldsymbol{F}$, respectively. $\boldsymbol{A}, \boldsymbol{E}$, Most cells in the rostral-caudal stripes of gpr $103 \boldsymbol{b}$-expressing neurons in the hindbrain do not colocalize with vglur2b. C, E, Caudal, but not rostral, hypothalamic gpr103b-expressing neurons colocalize with vglut2b. Similar colocalization patterns were observed using probes specific for vglut 1 and vglut2a (data not shown). Schematic diagram in lower left indicates region shown in $\boldsymbol{A}-\boldsymbol{D}$, with the brain shaded blue, and indicates rostral, caudal, and lateral axes. Dorsal views are shown. Scale bars: $\boldsymbol{A}-\boldsymbol{D}, 100 \mu \mathrm{m} ; \boldsymbol{E}, \boldsymbol{F}, 20 \mu \mathrm{m}$.

C-terminal 7 aa motif (GGFXFRF- $\mathrm{NH}_{2}$ ) that is critical for biological activity (Fukusumi et al., 2003; Jiang et al., 2003; do Rego et al., 2006; Navarro et al., 2006) and is conserved in all animals studied to date (Ukena et al., 2014). We found that the zebrafish genome contains a single qrfp ortholog that was incorrectly annotated as a noncoding RNA. This gene encodes for a 168 aa protein that contains the conserved C-terminal motif and a predicted 26 aa mature peptide (Fig. 1A). The QRFP preproprotein also contains an upstream Arg-Arg motif, as well as a Lys-Arg motif that is conserved with goldfish, that could generate $\mathrm{N}$-terminal elongated peptides of 54 or 60 aa, respectively, although these extended sequences have low homology with the mammalian peptides (Fig. 1B). $q r f p$ is expressed in glutamatergic hypothalamic neurons in zebrafish ISH experiments have shown that qrfp expression is largely restricted to the hypothalamus in all species studied, including human (Bruzzone et al., 2006), mouse (Takayasu et al., 2006), rat (Chartrel et al., 2003; Fukusumi et al., 2003; Kampe et al., 2006), quail (Ukena et al., 2010), and zebra finch (Tobari et al., 2011); although expression in other tissues, such as the human spinal cord, has been observed (Bruzzone et al., 2006). In particular, qrfp expression in mammals has been localized to the ventromedial hypothalamus, periventricular nucleus of the hypothalamus, and lateral hypothalamic area. Analysis in goldfish using RT-PCR identified QRFP expression in the hypothalamus, optic tectum, thalamus, and testis, but these results were not validated by ISH (Liu et al., 2009).

To determine where qrfp is expressed in zebrafish, we performed ISH using a $q r f p$-specific probe. We first observed $q r f p$ expression at $24 \mathrm{~h}$ post-fertilization (hpf) in a bilateral hypothalamic population of two to four neurons (Fig. 2A). At $120 \mathrm{hpf}$, at which time zebrafish larvae exhibit sleep/wake behaviors (Zhdanova et al., 2001; Prober et al., 2006), we observed qrfp expression in a bilateral population of 10-15 neurons in the hypothalamus (Fig. $2 B)$. This expression pattern persists in adult zebrafish, which contain $\sim 120$ qrfpexpressing neurons (Fig. 3J). At all developmental stages analyzed, qrfp expression in the brain was restricted to the hypothalamus. These observations indicate that the mammalian qrfp expression pattern is conserved in zebrafish, and the small number of $q r f p$-expressing neurons suggests that zebrafish may provide a simpler system to study the development and function of these neurons.

We next attempted to identify enhancer elements in the qrfp promoter that are sufficient to regulate gene expression in $q r f p$-expressing neurons. $q r f p$ is predicted to contain two exons separated by a short intron. We confirmed this gene structure using 5' RACE and found that the second exon contains the entire QRFP coding sequence. We cloned $1 \mathrm{~kb}$ of genomic DNA immediately upstream of the start codon, including the first noncoding exon and the intron, and found that this sequence was sufficient to drive transgene expression in qrfp-expressing neurons in transient injection experiments. As little as 475 bp of genomic sequence immediately $5^{\prime}$ to the start codon was sufficient to drive EGFP expression in qrfpexpressing neurons, but was somewhat less specific than the $1 \mathrm{~kb}$ sequence (data not shown). Transient injections using the $1 \mathrm{~kb}$ promoter often produced EGFP expression in body wall muscle, but little muscle expression was observed in stable transgenic lines. Expression in muscle in transient injection experiments and stable lines could be eliminated by including two copies of a 

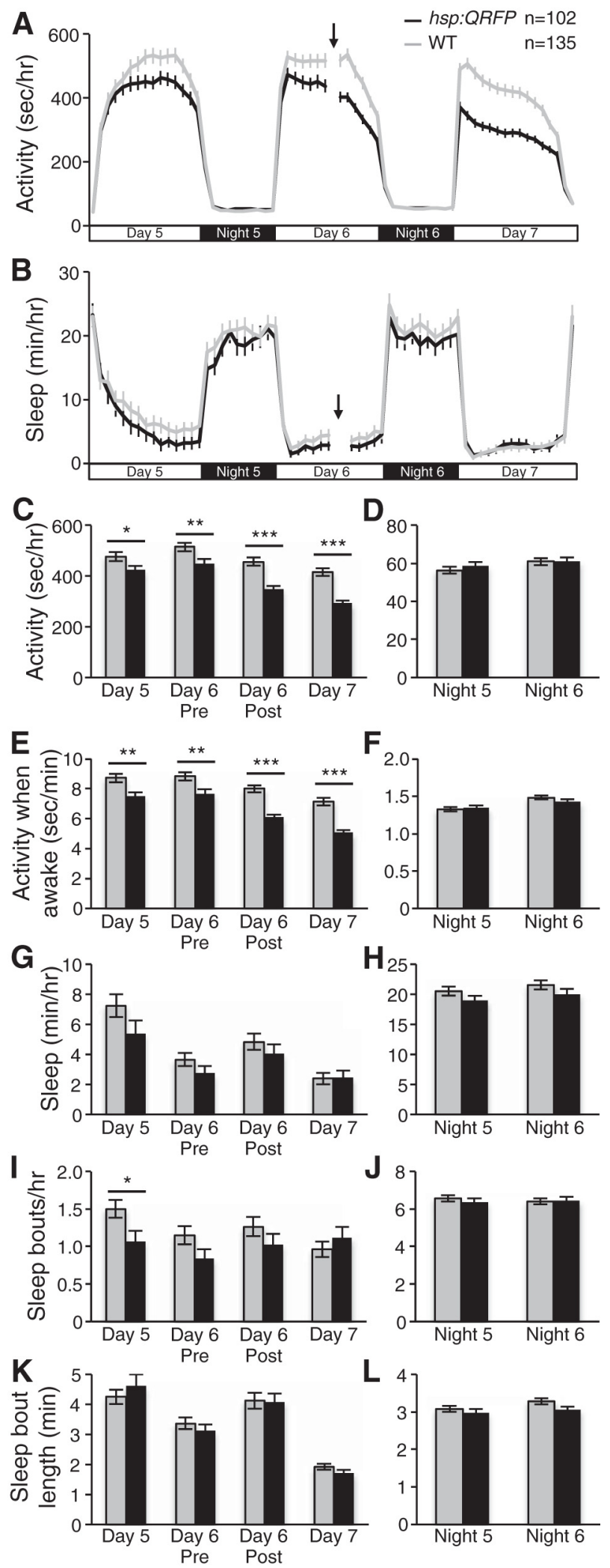

Figure 8. QRFP overexpression decreases locomotor activity during the day. A, $\boldsymbol{C}, \operatorname{Tg}$ (hsp: QRFP) larvae (black) exhibit less locomotor activity than their WT siblings (gray) on Day 5 and before heat shock on Day 6 (Day 6 pre), presumably due to leaky expression from the hsp promoter. However, transgenic larvae are much less active than controls during Day 6 after heat shock (Day 6 post) and exhibit an even stronger phenotype the following day. A, D, QRFP overexpression does not affect locomotor activity at night. $\boldsymbol{E}, \boldsymbol{F}$, QRFP overexpression also increases locomotor activity when awake during the day but not at night. $\boldsymbol{B}, \mathbf{G}-\mathbf{L}$, QRFP overexpression does not affect the total amount of $\operatorname{sleep}(\boldsymbol{B}, \boldsymbol{G}, \boldsymbol{H})$, or the number $(\boldsymbol{I}, \boldsymbol{J})$ or length $(\boldsymbol{K}, \boldsymbol{L})$

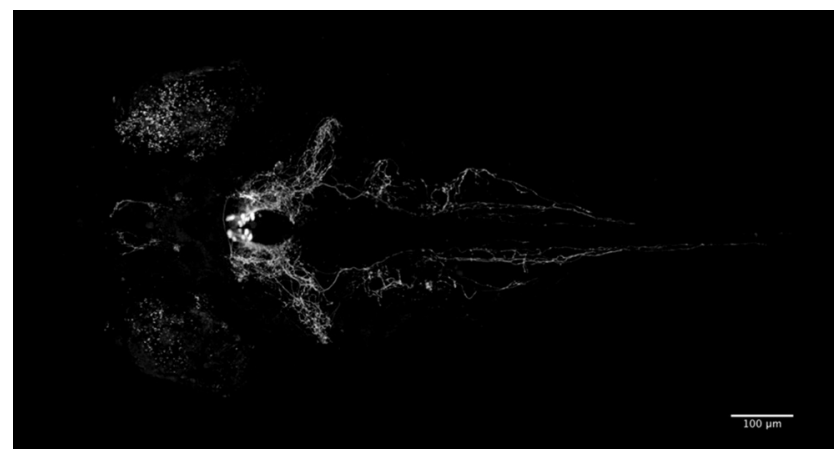

Movie 1. QRFP neuron projections. The movie shows a maximum intensity projection of a two-photon $215 \mu \mathrm{m}$ stack of a live $8 \mathrm{dpf} \operatorname{Tg}$ (qrfp:Brainbow) larva that rotates by $90^{\circ}$ along the longitudinal axis. This larva did not undergo Cre-mediated recombination, and thus only expresses tdTomato. The larva was treated with 1-phenyl 2-thiourea (PTU) during development to inhibit pigment formation. The qrfp-expressing neurons project widely in the hypothalamus and hindbrain, send sparse projections to the forebrain, and project down the spinal cord. The first frame of the movie is shown in Figure 2D. Rostral is to the left and dorsal is at the top of the last frame. The bilaterally symmetric speckled regions on the left are autofluorescence in the eyes. The images consist of a tiled stack of eight panels, $512 \times 512$ pixels each, acquired using a $40 \times$ objective.

neuron-restrictive silencing element (NRSE; Bergeron et al., 2012; Xie et al., 2013) immediately $5^{\prime}$ to the $q r f p$ promoter (data not shown). We were able to identify a stable transgenic line using the $1 \mathrm{~kb}$ promoter without NRSE elements that produced strong EGFP expression in $q r f p$-expressing neurons. To determine the specificity of this promoter, we performed FISH using a qrfpspecific probe together with immunohistochemistry using an EGFP-specific antibody (Fig. 2C). We found that $97 \pm 1 \%$ of EGFP-positive neurons were also positive for qrfp mRNA, and $98 \pm$ $1 \%$ of $q r f p$ mRNA-positive neurons were also positive for EGFP ( $n=113$ neurons in 10 brain hemispheres), indicating that this transgenic line is specific for $q r f p$-expressing neurons. Using $\operatorname{Tg}(q r f p$ : EGFP) (data not shown) and $\operatorname{Tg}(q r f p: B r a i n b o w)$ (Fig. 2D, Movie 1) larvae, we observed extensive QRFP neuron projections in the hypothalamus, sparse projections to the forebrain, and projections to the hindbrain that extend down the spinal cord.

To characterize qrfp-expressing neurons in more detail, we performed double FISH using probes specific for $q r f p$, and markers for specific neurotransmitters and neuropeptides. We found that all qrfp-expressing neurons colocalize with markers for glutamatergic neurons, including vglut2b (Fig. 2E), vglut1 (data not shown), and vglut2a (data not shown), and do not colocalize with markers for GABAergic neurons, including gad67 (Fig. 2F) and gad65 (data not shown). These results suggest that qrfp neurons produce the excitatory neurotransmitter glutamate but not the inhibitory neurotransmitter GABA. To compare the localization of larval zebrafish qrfp-expressing neurons to other hypothalamic neuron subtypes (Fig. 3), we performed double FISH using WT larvae or single FISH using $\operatorname{Tg}(q r f p: E G F P)$ larvae, using probes specific for $q r f p$ and $a v p$, ccka, cckb, crhb, hypocretin (hcrt), oxt, sst1.1, vip, and the dopaminergic neuron marker th1. We found that qrfp-expressing neurons are located dorsal relative to neurons expressing several of these genes in the hypothalamus, including avp, ccka, cckb, sst1.1, and vip. qrfp expression is also observed slightly caudal to oxt and slightly rostral to

$\leftarrow$

of sleep bouts during the day or night. Time of heat shock is indicated by arrows and gaps in activity $(\boldsymbol{A})$ and sleep $(\boldsymbol{B})$ line graphs on Day 6. Line and bar graphs represent the mean \pm SEM. $n$ indicates the number of larvae analyzed. ${ }^{*} p<0.05,{ }^{* *} p<0.01,{ }^{* * *} p<0.001$ for pairwise comparisons of Tg(hsp:QRFP) and WT larvae using Student's $t$ test. 


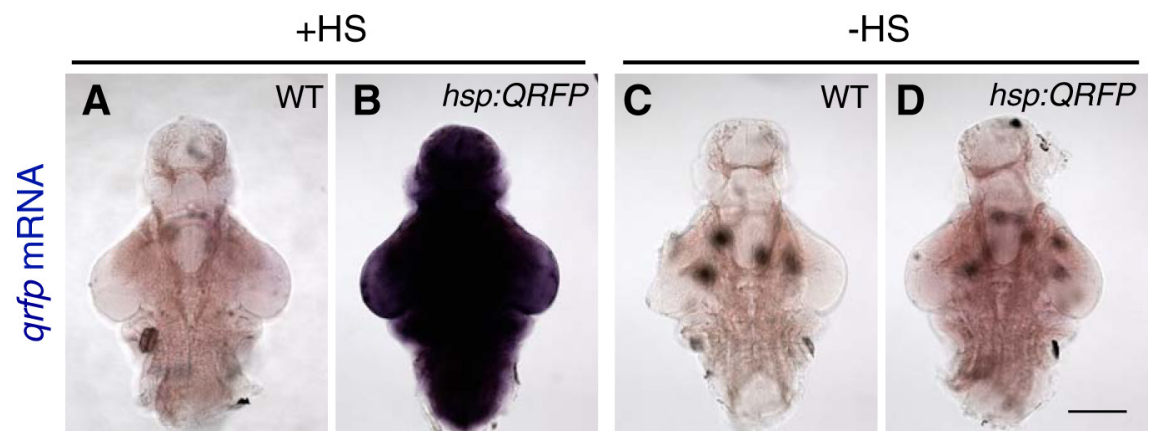

Figure 9. $T g(h s p: Q R F P)$ larvae exhibit leaky qrfp mRNA expression in the absence of a heat shock. Representative whole-mount brains from $5 \mathrm{dpf} \operatorname{Tg}$ (hsp:QRFP) larvae and their nontransgenic WT siblings are shown. $\boldsymbol{A}-\boldsymbol{D}$, Larvae were fixed $1 \mathrm{~h}$ after a $1 \mathrm{~h}$ heat shock at $37^{\circ} \mathrm{C}(\boldsymbol{A}, \boldsymbol{B})$ and were compared with non-heat shocked larvae that were maintained at $28.5^{\circ} \mathrm{C}(\boldsymbol{C}, \boldsymbol{D})$. Transgenic heat shocked larvae exhibit robust and nearly ubiquitous qrfp expression $(\boldsymbol{B})$ compared with identically treated WT siblings $(\boldsymbol{A})$. Transgenic larvae that were not heat shocked exhibit mildly elevated qrfp mRNA levels throughout much of the brain (D) compared with identically treated WT siblings (C), indicating leaky qrfp expression in non-heat shocked $T g(h s p: Q R F P)$ larvae. Endogenous qrfp is not visible because development of the ISH reaction was stopped before endogenous qrfp could be detected. Transgenic and nontransgenic sibling larvae were processed for ISH in the same tubes and genotyped after imaging, thus allowing comparison of relatively subtle differences in qrfp mRNA levels. Scale bar, $300 \mu \mathrm{m}$. Large spots (in $\boldsymbol{A}, \boldsymbol{C}, \boldsymbol{D}$ ) are pigment cells.

the hypothalamic cluster of th1-expressing neurons. qrfp-expressing neurons are also intermingled with neurons that express $c r h b$ and $h c r t$. We occasionally observed colocalization of $q r f p$ and $c r h b$ in one or two neurons, but never observed colocalization of qrfp and $h \mathrm{crt}(n$ $>50$ brains). We also examined qrfp-expressing neurons, and compared their location to that of hcrt-expressing neurons, in adult $T g(q r f p: E G F P) ; T g(h c r t: m R F P)$ double transgenic animals (Liu et al., 2015) that were fixed and cleared using PACT (Yang et al., 2014; Fig. $3 J)$. Similar to larval stages, we observed that QRFP neurons $(\sim 120$ cells) and Hcrt neurons ( $\sim 60$ cells) are localized near each other in the hypothalamus, but do not colocalize. These results indicate that qrfp is expressed in a population of hypothalamic neurons that is distinct from several other hypothalamic cell types, suggesting that these neurons may have a distinct function.

\section{The QRFP receptors Gpr103a/QRFPRA and Gpr103b/QRFPRB are conserved in zebrafish}

Several studies have shown that the G-protein-coupled receptor Gpr103 (also known as AQ27 and SP9155) acts as a receptor for QRFP-derived peptides (Fukusumi et al., 2003; Jiang et al., 2003; Takayasu et al., 2006). The human genome contains a single gpr103 gene (Lee et al., 2001), whereas two paralogs, gpr103a and gpr103b, are present in rodents (Kampe et al., 2006; Takayasu et al., 2006). Similar to rodents, we found that the zebrafish genome contains two gpr103 paralogs, denoted gpr103a (qrfpra) and gpr103b (qrfprb; Fig. 4). The zebrafish paralogs share $80 \%$ amino acid identity with each other, and each zebrafish paralog is $\sim 60 \%$ identical to each mouse paralog.

\section{gpr103a and $g p r 103 b$ are expressed in distinct neuronal} populations in the larval zebrafish brain

To determine the expression patterns of the putative zebrafish QRFP receptors, we performed ISH using probes specific for gpr103a and gpr103b. gpr103b expression was first detected at 48 hpf in two distinct hypothalamic nuclei (Fig. 5A-C). At $120 \mathrm{hpf}$, we observed expression in several brain regions, including a large hypothalamic expression domain (Fig. 5D,E), a series of rostralcaudal stripes in the hindbrain (Fig. 5D), and several scattered neuronal populations in the midbrain and hindbrain (Fig. $5 D, E)$. We were unable to detect gpr103a expression until 120 hpf, at which point we observed expression in two clusters of neurons in the ventral hypothalamus (Fig. $5 F$ ) and dorsally as four paired clusters of neurons in the lateral midbrain (Fig. 5G). Thus, similar to rodents (Fukusumi et al., 2003; Kampe et al., 2006; Takayasu et al., 2006; Bruzzone et al., 2007), the zebrafish gpr103 paralogs are expressed in apparently nonoverlapping regions of the hypothalamus and hindbrain. These regions are consistent with QRFP signaling playing a role in regulating a variety of homeostatic functions, possibly including sleep.

To characterize gpr103b-expressing neurons in more detail, we performed double FISH using probes specific for gpr103b and several neurotransmitter subtype markers. We found that the broad domain of hypothalamic gprio3bexpressing cells contains two territories. Rostral gpr103b-expressing cells colocalize with a GABAergic marker (Fig. 6), whereas caudal gpr103b-expressing cells colocalize with a glutamatergic marker (Fig. 7). We also examined the rostral-caudal stripes of gpr103b-expressing cells in the hindbrain because this expression pattern appeared to be similar to previously described alternating stripes of glutamatergic and GABAergic neurons in the larval zebrafish hindbrain (Higashijima et al., 2004). We found that many of these gpr103bexpressing cells colocalized with GABAergic markers (Fig. 6), whereas few of these cells colocalized with glutamatergic markers (Fig. 7). We were unable to perform a similar analysis for $g$ pr103a because its expression was too low to obtain robust FISH labeling. These results indicate that $g$ pr $103 b$ is expressed in both excitatory and inhibitory neurons in regions of the larval zebrafish brain that are consistent with the regulation of sleep.

\section{QRFP overexpression decreases daytime locomotor activity}

The expression of QRFP in the hypothalamus, and of its receptors in the hypothalamus and brainstem, suggested that QRFP signaling might affect locomotor activity and/or sleep. Indeed, several studies in rodents (do Rego et al., 2006; Kampe et al., 2006; Moriya et al., 2006; Takayasu et al., 2006) have shown that intracerebroventricular injection of QRFP peptides can affect locomotor activity, although the effects were transient and inconsistent in different studies. The discrepancies may arise from the use of QRFP peptides that were synthesized and modified in vitro, and thus may differ from mature peptides that are generated from the full-length protein in vivo. Furthermore, the technically challenging and invasive nature of these injections, the small number of animals studied, and the transient effects on behavior may confound the results.

To avoid these potential problems, we used a genetic approach to overexpress the full-length QRFP gene in zebrafish larvae using a HS-inducible promoter ( $h s p$; Halloran et al., 2000), and monitored effects on behavior using a previously described locomotor activity assay (Prober et al., 2006). This approach is noninvasive, generates the full-length QRFP protein that is processed and modified in vivo, and allows the behavior of many animals to be studied before and after transgene overexpression. We found that $T g(h s p: Q R F P)$ larvae were somewhat less active than WT larvae pre-HS ( $11 \%$ decrease; $p<0.05$ by Student's $t$ test; Fig. $8 A, C$ ), likely due to leaky expression of the transgene from the $h s p$ promoter (Fig. 9). However, locomotor activity levels were more 

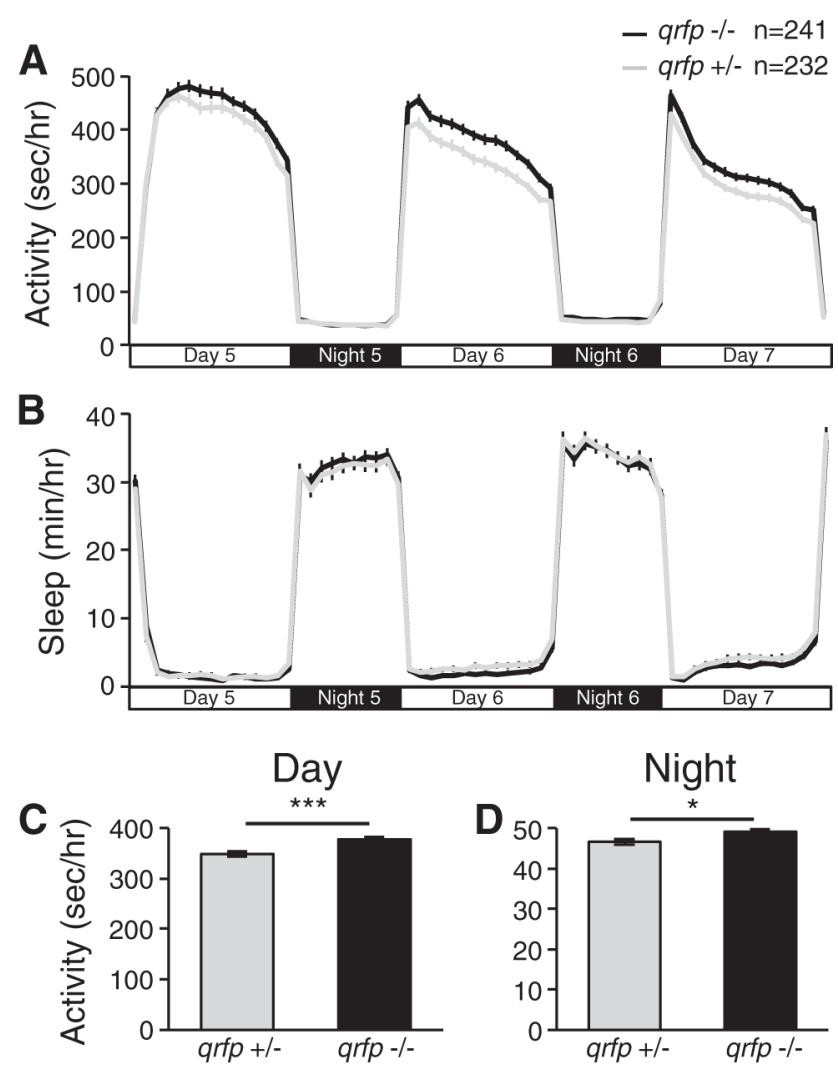

E
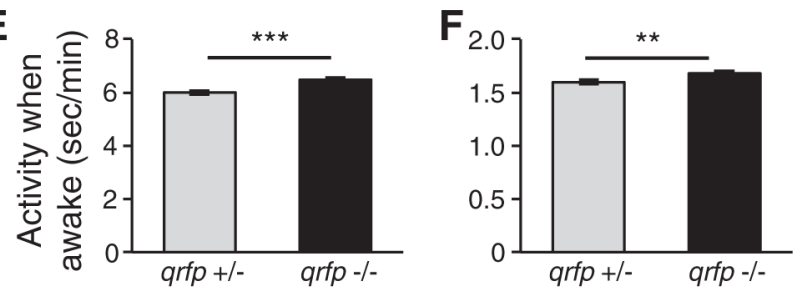

G
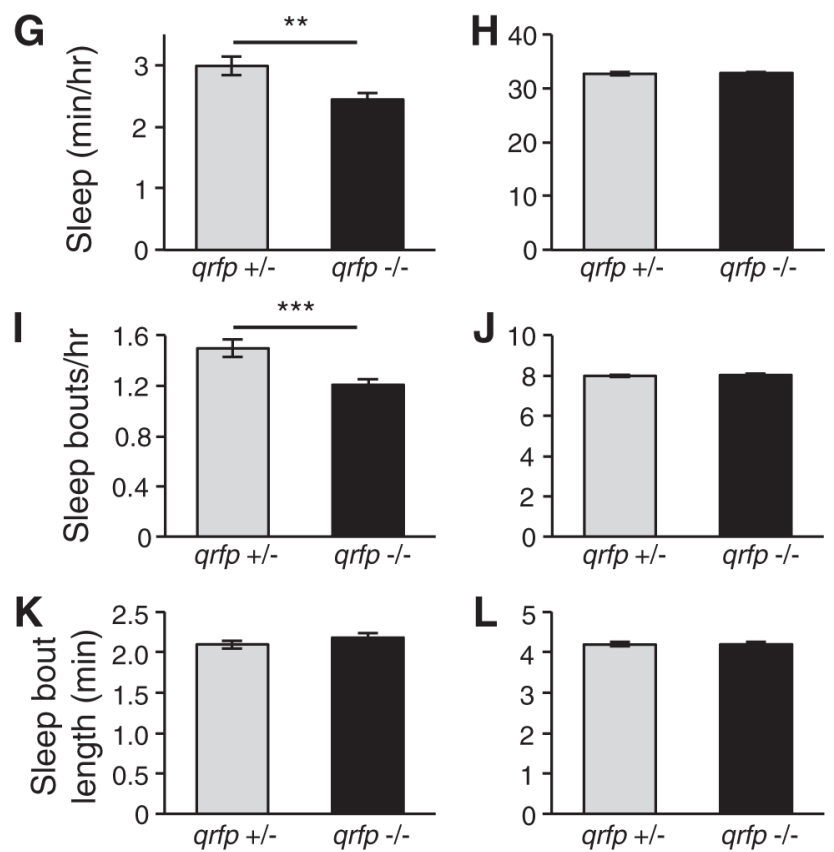

Figure 10. qrfp mutant larvae are more active and sleep less during the day. $\boldsymbol{A}, \boldsymbol{C}, \boldsymbol{D}$, qrfp $^{-1-}$ larvae (black) are more active during the day $(\boldsymbol{A}, \boldsymbol{C})$ and slightly more active at night (D) compared with their qrfp ${ }^{+/}$siblings (gray). $\boldsymbol{E}, \boldsymbol{F}$, qrfp $^{-1-}$ larvae are also more active when awake compared with controls. $\boldsymbol{B}, \boldsymbol{G}$, qrfp $^{-1-}$ larvae sleep less during the day significantly reduced in $T g(h s p: Q R F P)$ larvae compared with WT larvae immediately following heat shock (24\% decrease; $p<$ 0.001 by Student's $t$ test; Fig. $8 A, C)$, and the effect was even stronger the next day ( $30 \%$ decrease; $p<0.001$ by Student's $t$ test; Fig. $8 A, C)$. Comparison of WT and $T g(h s p: Q R F P)$ locomotor activity levels before (Day 5) and after (Day 7) heat shock revealed a significant genotype-heat shock interaction (two-way ANOVA, $p<0.05$ ), indicating that locomotor activity is affected by heat shock differently in $T g(h s p: Q R F P)$ and WT larvae, and consistent with heat shock significantly decreasing locomotor activity in $T g$ (hsp:QRFP) larvae. QRFP-overexpressing larvae also exhibited less activity while awake (30\% decrease; $p<0.001$ by Student's $t$ test; Fig. $8 E$ ) during the day. There was no effect of QRFP overexpression on locomotor activity or activity while awake at night (Fig. 8A,D,F). Sleep in zebrafish larvae has been defined as a period of inactivity that lasts for $\geq 1 \mathrm{~min}$, because this is associated with an increased arousal threshold (Prober et al., 2006; Elbaz et al., 2012). We found that the total amount of sleep, and the number and length of sleep bouts, during the day and night was indistinguishable for $T g(h s p: Q R F P)$ larvae compared with their WT siblings following the overexpression of QRFP (Fig. 8B, G-L). Thus, QRFP overexpression suppresses daytime locomotor activity without inducing sleep in zebrafish larvae.

\section{qrfp mutant zebrafish larvae are more active and sleep less during the day}

To analyze the function of endogenous qrfp, we used the ZFN method (Foley et al., 2009) to mutate the qrfp gene (Chen et al., 2013). We isolated a mutant line containing a 4 bp insertion, which results in a premature stop codon that is predicted to generate a 43 aa protein that lacks all known QRFP functional domains (Fig. 1B). These mutants are homozygous viable and fertile, and lack obvious developmental defects (data not shown). Using ISH, we observed reduced $q r f p$ expression in $q r f p^{-1-}$ larvae compared with their $q r f p^{+/-}$and WT siblings, consistent with nonsense-mediated decay of the mutant mRNA (data not shown; Isken and Maquat, 2007). Based on the QRFP overexpression phenotype, we hypothesized that qrfp mutant larvae would exhibit increased locomotor activity. Indeed, we found that $q_{r f p}{ }^{-1-}$ larvae exhibited significantly more locomotor activity (Fig. 10A,C,D) and locomotor activity while awake (Fig. 10 E, F) compared with their $q r f p^{+/-}$siblings. Consistent with the QRFP overexpression phenotype, this effect was stronger during the day (Fig. 10A,C-F; day locomotor activity: $8 \%$ increase, $p<0.001$; night locomotor activity: $5 \%$ increase, $p<0.05$; day locomotor activity while awake: $8 \%$ increase, $p<0.001$; night locomotor activity while awake: $5 \%$ increase, $p<0.01$; by Student's $t$ test). We also observed that $q r f p^{-l-}$ larvae slept significantly less during the day ( $18 \%$ decrease, $p<0.01$ by Student's $t$ test; Fig. $10 B, G$ ), but not at night (Fig. $10 H$ ), compared with their $q r f p^{+1-}$ siblings. The $q r f p^{-1-}$ sleep defect was due to a decrease in the number of sleep bouts (Fig. 10I), with no effect on the lengths of these bouts (Fig. 10K), indicating that daytime bouts of wakefulness are consolidated in $q r f p^{-1-}$ larvae compared with

compared with controls. $\boldsymbol{I}, \boldsymbol{K}$, The sleep phenotype is due to a decrease in the number of sleep bouts (I) with no effect on the length of sleep bouts $(\boldsymbol{K})$. The amount of sleep $(\boldsymbol{H})$ and number $(\boldsymbol{N})$ and length $(\boldsymbol{L})$ of sleep bouts are normal for qrfp $^{-1-}$ larvae at night. Line and bar graphs represent the mean \pm SEM. $n$ indicates the number of larvae analyzed. ${ }^{*} p<0.05,{ }^{* *} p<0.01,{ }^{* * *} p<0.001$ for pairwise comparisons of grfp $^{-1-}$ and grfp $^{+1-}$ larvae using Student's $t$ test. 

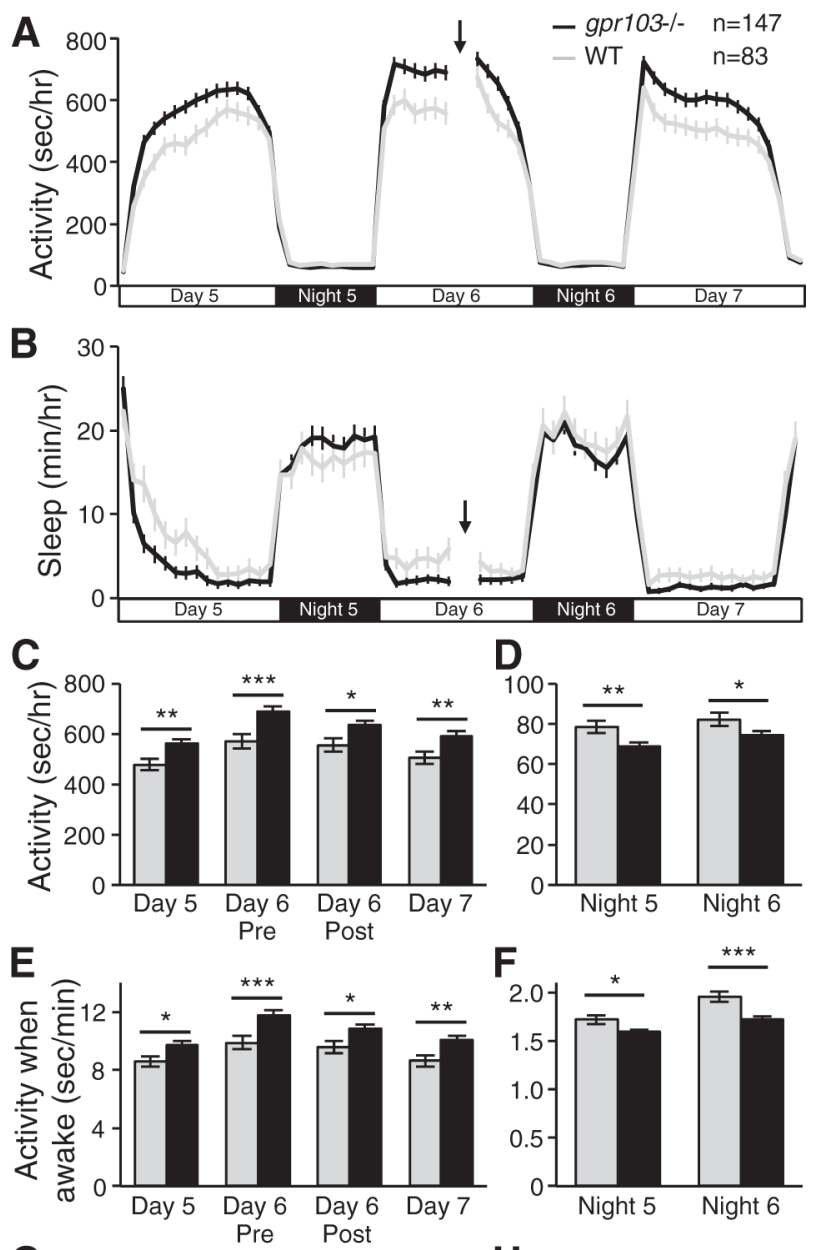

G
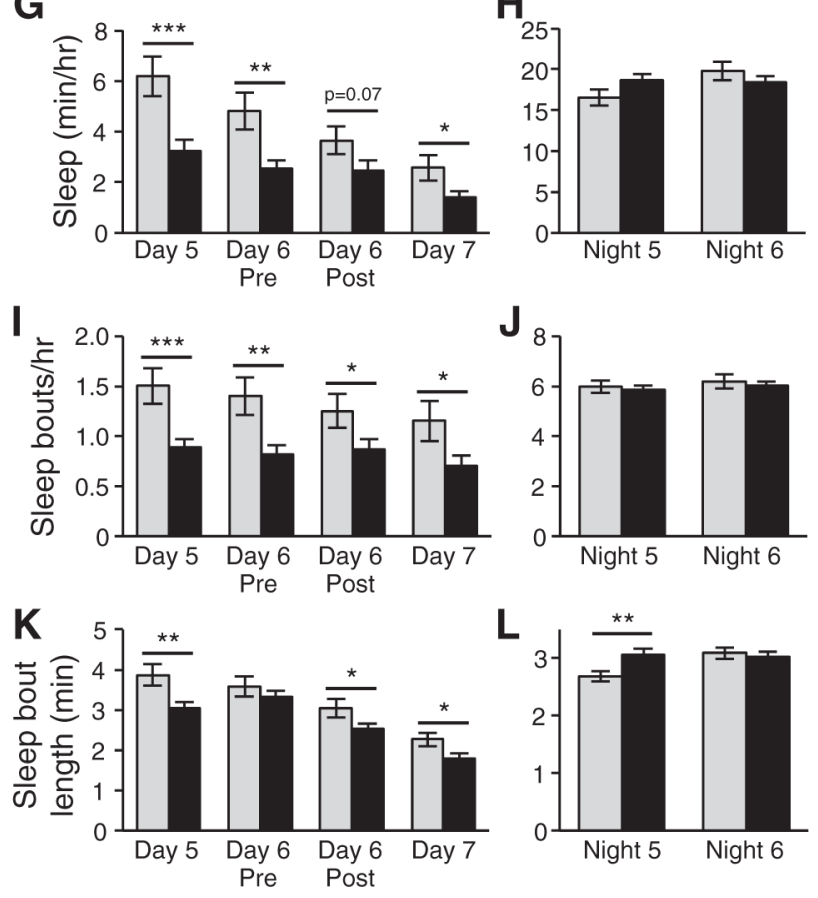

Figure 11. gpr103a $a^{-1-} ; g$ pr103b $b^{-/-}$larvae are more active and sleep less during the

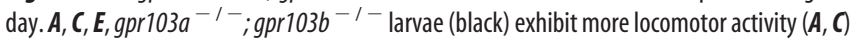
and locomotor activity while awake $(\boldsymbol{E})$ during the day compared with related WT larvae (gray).

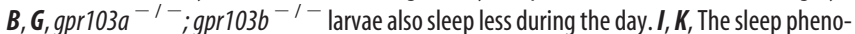
type is primarily due to a decrease in the number of sleep bouts $(I)$, with less or no effect on the

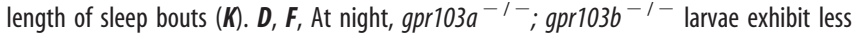

controls. We conclude that endogenous qrfp is required to maintain normal daytime levels of sleep and locomotor activity.

\section{gpr103a; gpr103b double-mutant zebrafish larvae are more} active and sleep less during the day

To determine the downstream signaling pathway involved in QRFP-regulated sleep, we generated zebrafish containing mutations in gpr103a and gpr103b using the TALEN (Sander et al., 2011) and ZFN (Foley et al., 2009) methods, respectively (Chen et al., 2013). We isolated a gpr103a mutant containing an $11 \mathrm{bp}$ deletion, which introduces a shift in the reading frame before the first predicted transmembrane domain, resulting in an early stop codon and generating a predicted 105 aa protein (Fig. 4A). We isolated a gpr103b mutant containing a 4 bp deletion, which introduces a shift in the reading frame in the predicted fifth transmembrane domain, resulting in an early stop codon, and generating a predicted 220 aa protein (Fig. 4A). Both mutant proteins should be unable to properly insert into the cell membrane due to the loss of transmembrane domains, and should therefore be nonfunctional. We found that zebrafish homozygous for each single mutant, as well as double-homozygous mutants, were viable and fertile, with no obvious developmental defects (data not shown). To determine whether these genes are required for normal levels of locomotor activity and sleep, we compared the behavior of $g$ pr103a $a^{-1-} ; g$ pr103b $b^{-1-}$ larvae to that of related WT larvae (see Materials and Methods). Similar to qrfp mutants, gpr103a $a^{-1-}$; gpr103b $b^{-1-}$ larvae exhibited increased locomotor activity ( $17 \%$ increase; $p<0.001$ by Student's $t$ test; Fig. $11 A, C)$, increased locomotor activity while awake ( $17 \%$ increase; $p<0.001$ by Student's $t$ test; Fig. $11 E$ ) and decreased sleep ( $45 \%$ decrease; $p<0.001$ by Student's $t$ test; Fig. $11 B, G)$ during the day compared with WT controls. Consistent with qrfp mutant larvae, the $g$ pr103a $a^{-1-}$; gpr103b $b^{-1-}$ sleep phenotype was mainly due to a decrease in the number of sleep bouts (Fig. 11I), with less or no effect on the length of these bouts (Fig. $11 \mathrm{~K}$ ). In contrast to qrfp mutant larvae, $g \mathrm{pr} 103 a^{-1-}$; $g$ pr103 $b^{-1-}$ larvae also exhibited decreased locomotor activity ( $11 \%$ decrease; $p<0.001$ by Student's $t$ test) and locomotor activity while awake ( $10 \%$ decrease; $p<0.001$ by Student's $t$ test) at night (Fig. 11D,F) compared with controls. This observation suggests that Gpr103a and Gpr103b may have a QRFPindependent function at night. To control for any potential effects of a heat shock on behavior, and thus to allow comparison with the QRFP overexpression experiment, we performed a heat shock during the afternoon on Day 6, and monitored behavior before and after the heat shock. We found that the mutant phenotype compared with WT controls was similar before and after the heat shock (Fig. 11A-L). Together, these results indicate that gpr103a and gpr103b are required to maintain normal daytime levels of sleep and locomotor activity, similar to qrfp, consistent with Gpr103a and Gpr103b functioning as receptors for QRFP in vivo. locomotor activity $(\boldsymbol{D})$ and locomotor activity while awake $(\boldsymbol{F})$ compared with WT larvae. The amount of sleep $(\boldsymbol{H})$ and number $(\boldsymbol{C})$ and length $(\boldsymbol{L})$ of sleep bouts are largely normal for $g p r 103 a^{-1-}$; gpr1036 ${ }^{-1-}$ larvae at night. A heat shock applied during the afternoon on Day 6 [indicated by arrows and gaps in activity $(\boldsymbol{A})$ and sleep $(\boldsymbol{B})$ line graphs] has no effect on the mutant locomotor activity or sleep phenotypes compared with WT larvae. Line and bar graphs represent the mean \pm SEM. $n$ indicates the number of larvae analyzed. ${ }^{*} p<0.05,{ }^{* *} p<0.01,{ }^{* * *} p<0.001$ for pairwise com-

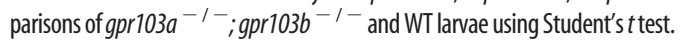


The QRFP overexpression behavioral phenotype is abolished in gpr103a; gpr103b double-mutant larvae To test whether Gpr103a and Gpr103b are functional receptors for QRFP, we compared the effect of QRFP overexpression on locomotor activity in WT larvae to gpr103a-1- gpr103b-1- larvae (Fig. 12). Consistent with our previous experiments, QRFP overexpression decreased locomotor activity during the day of heat shock and the following day (day pre-HS: $12 \%$ decrease, $p=0.42$; day post-HS: $27 \%$ decrease, $p<0.01$; following day: $25 \%$ decrease, $p<0.01$, by Tukey's HSD test), whereas gpr103a $a^{-1-} ; g$ pr103b $b^{-1-}$ double-mutant larvae exhibited increased daytime locomotor activity (day pre-HS: $56 \%$ increase, $p<0.001$; day post-HS: $24 \%$ increase, $p<0.05$; following day: $29 \%$ increase, $p<0.01$, by Tukey's HSD test). Strikingly, the QRFP overexpression-induced decrease in daytime locomotor activity was abolished in gpr103a-1- gpr103b ${ }^{-1-}$ larvae $(p=$ 0.92 , by Tukey's HSD test), suggesting that Gpr103a and Gpr103b are functional receptors for QRFP in zebrafish.

\section{QRFP expression does not exhibit a circadian oscillation}

Because QRFP gain-of-function and lossof-function phenotypes were largely restricted to the day, we hypothesized that endogenous qrfp expression, and thus QRFP signaling, might be regulated in a circadian manner. To test this hypothesis, we raised larvae under standard $14 \mathrm{~h} / 10 \mathrm{~h}$ light/dark conditions until $6 \mathrm{dpf}$, and then transferred them to constant dark. In this "free-running" condition, WT larvae maintain molecular and behavioral circadian rhythms in the absence of daily light/dark cues (Kaneko and Cahill, 2005). After $24 \mathrm{~h}$ in constant dark, we isolated samples every $6 \mathrm{~h}$ for $24 \mathrm{~h}$, and assayed qrfp levels using quantitative RT-PCR (qRT-PCR). In contrast to the circadian clock gene period $1 b$ (per $1 b$ ), whose expression oscillated in a circadian manner, we failed to observe a circadian oscillation of qrfp expression (Fig. 13A). Consistent with this result, using ISH we observed similar qrfp mRNA levels during both subjective day and subjective night in larvae that were entrained in standard light/dark conditions and fixed after transfer to constant dark (Fig. 13B). These observations suggest that qrfp expression is not regulated by the circadian clock.

\section{QRFP overexpression decreases locomotor activity and increases sleep in larvae that lack behavioral circadian rhythms}

Although we found that the circadian clock does not regulate $q r f p$ expression, the fact that QRFP gain-of-function and loss-offunction phenotypes are more prominent during the day suggested that the circadian clock might modulate QRFP function. Alternatively, the ability of overexpressed QRFP to suppress daytime locomotor activity may depend on the presence of light and be independent of the circadian clock. To test this hypothesis, we raised and tested larvae in constant light conditions, which prevents the development of behavioral circadian rhythms (Hurd and Cahill, 2002). We found that QRFP overexpression decreased locomotor activity ( $20 \%$ decrease; $p<0.001$ by Student's $t$ test) and locomotor activity while awake (19\% decrease; $p<$ 0.001 by Student's $t$ test) compared with nontransgenic WT siblings during the $30 \mathrm{~h}$ that we monitored behavior following heat shock (Fig. 14A, C,D). QRFP overexpression also increased sleep under these conditions ( $34 \%$ increase; $p<0.05$ by Student's $t$ test; Fig. $14 B, E$ ). This result suggests that the QRFP overexpression phenotype is specific to the day due to the presence of light and not due to circadian regulation of QRFP function.

As an additional test of whether the circadian clock modulates QRFP function, we raised and tested larvae in constant dark conditions. Similar to larvae raised and tested in constant light, QRFP overexpression in constant dark decreased locomotor activity ( $16 \%$ decrease; $p<0.01$ by Student's $t$ test) and locomotor activity while awake ( $16 \%$ decrease; $p<0.001$ by Student's $t$ test) compared with nontransgenic WT siblings (Fig. 15A,C,D). However, in contrast to constant light, QRFP overexpression had no effect on the amount of sleep in constant dark (Fig. 15B,E), although it did affect sleep architecture (Fig. 15F, G). Together, these results suggest that the circadian clock does not modulate QRFP function, but rather that the effects of QRFP overexpression on behavior are stronger in light than in dark.

To more directly test the hypothesis that QRFP overexpression inhibits locomotor activity in a light-dependent manner, we entrained larvae for $4 \mathrm{~d}$ in standard light/dark conditions, and on the morning of the fifth day of development we exposed them to alternating $1 \mathrm{~h}$ periods of lights on and off for $72 \mathrm{~h}$ (Fig. 16). We performed a heat shock during the afternoon of the sixth day of development, and compared the locomotor activity of $\operatorname{Tg}(h s p$ : QRFP) larvae to their WT siblings during light and dark periods 


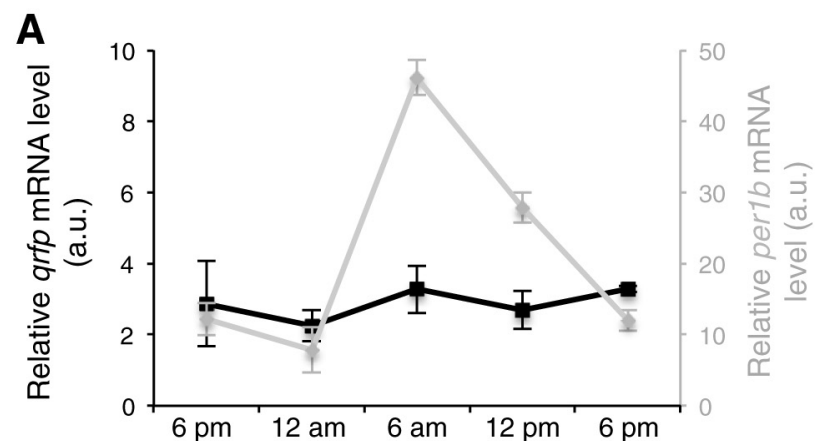

B
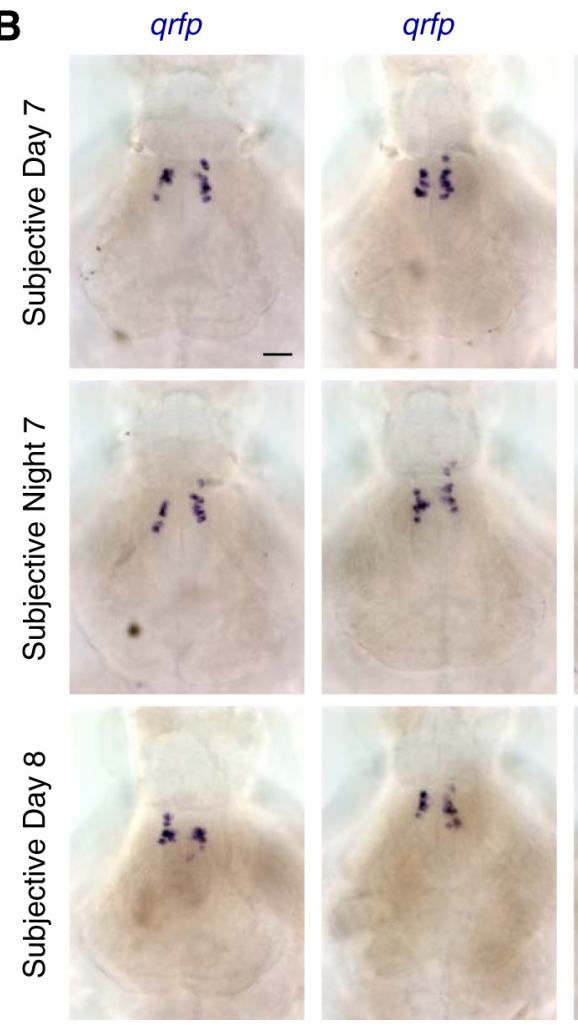

qrfp

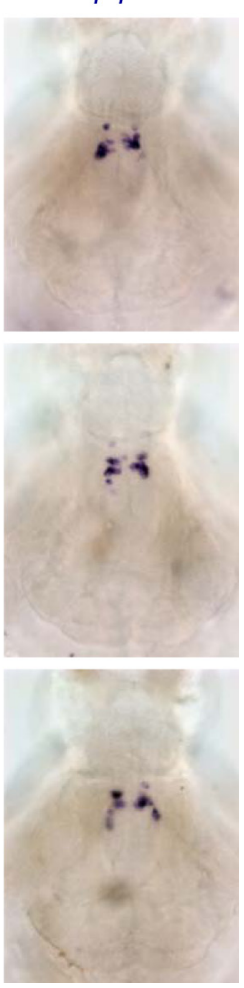

Figure 13. grfp expression is not regulated by the circadian clock. $A$, WT larvae were entrained in $14 \mathrm{~h} / 10 \mathrm{~h} \mathrm{light} /$ dark conditions and transferred to constant dark at 6:00 P.M. at $6 \mathrm{dpf}$. Starting $24 \mathrm{~h}$ later, mRNA samples were collected every $6 \mathrm{~h}$ for $24 \mathrm{~h}$. qRT-PCR shows that the level of per $1 b$ mRNA (gray) oscillates in a circadian manner while the level of arfp mRNA (black) does not. Data points represent the mean \pm SEM. $\boldsymbol{B}$, WT larvae were entrained in $14 \mathrm{~h} / 10 \mathrm{~h}$ light/dark conditions and transferred to constant dark at 12:00 P.M. at 6 dpf. Starting $24 \mathrm{~h} \mathrm{later,}$ larvae were fixed every $12 \mathrm{~h}$. ISH using a qrfp-specific probe shows no difference in qrfp expression during subjective day or subjective night. Each image is a $20 \mu \mathrm{m}$ sum-of-slices projection. Three representative larval brains are shown for each time point. Scale bar, $50 \mu \mathrm{m}$.

before and after heat shock. Before heat shock, there was no significant difference in the amount of locomotor activity between transgenic and WT larvae during either the light ( $p=0.98$, by Tukey's HSD test) or dark ( $p=0.68$, by Tukey's HSD test) periods (Fig. 16A, $B, D, E$ ). In contrast, QRFP-overexpressing larvae were significantly less active than their WT siblings during light periods ( $p<0.05$, by Tukey's HSD test), while there was no difference during dark periods ( $p=0.83$, by Tukey's HSD test; Fig. 16A, $C, D, E)$. Because the amount of locomotor activity for both genotypes varied depending on the circadian time, we also calculated the ratio of transgenic/WT locomotor activity during each $1 \mathrm{~h}$ light or dark trial, and compared these ratios before and after heat shock. For dark trials, there was no significant differ-
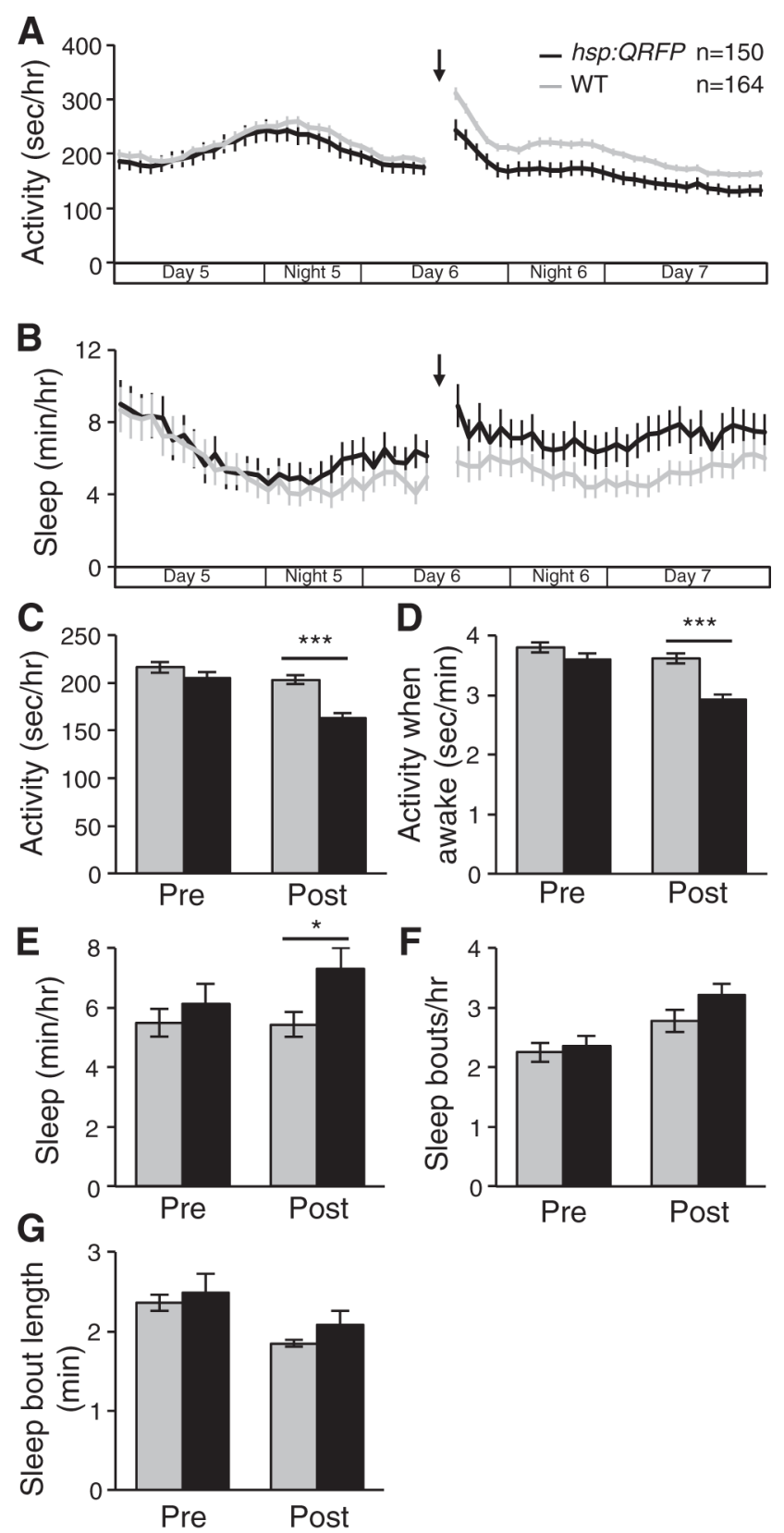

Figure 14. QRFP overexpression decreases locomotor activity and increases sleep in larvae raised and tested in constant light. $\boldsymbol{A}-\boldsymbol{E}$, When raised and tested in constant light, $T g$ (hsp:QRFP) larvae (black) exhibit less locomotor activity $(\boldsymbol{A}, \boldsymbol{C})$, less activity when awake $(\boldsymbol{D})$, and more sleep $(\boldsymbol{B}, \boldsymbol{E})$ than their WT siblings (gray) following a heat shock given during Day 6 of development (indicated by arrows and gaps in line graphs). $\boldsymbol{F}, \mathbf{G}$, Analysis of sleep architecture reveals small but not statistically significant increases in both the number $(\boldsymbol{F})$ and length $(\boldsymbol{G})$ of sleep bouts. The $x$-axes in $\boldsymbol{A}$ and $\boldsymbol{B}$ indicate time periods that correspond to day and night in standard light/dark conditions. Line and bar graphs represent the mean \pm SEM. Bar graphs quantify values for $30 \mathrm{~h}$ pre-heat shock and post-heat shock. $n$ indicates the number of larvae analyzed. ${ }^{*} p<0.05,{ }^{* *} p<0.001$ for pairwise comparisons of $\mathrm{Tg}$ (hsp:QRFP) and WT larvae using Student's $t$ test.

ence post-HS ( $1.09 \pm 0.03)$ compared with pre-HS $(1.14 \pm 0.04$; $p=0.74$, by Tukey's HSD test; Fig. 16F). In contrast, for light trials there was a significant decrease after heat shock compared with before heat shock (pre-HS, $0.97 \pm 0.01$; post-HS, $0.84 \pm$ $0.01 ; p<0.05$, by Tukey's HSD test; Fig. $16 F$ ). These results indicate that QRFP overexpression decreases locomotor activity in the context of light, but not dark, conditions. 

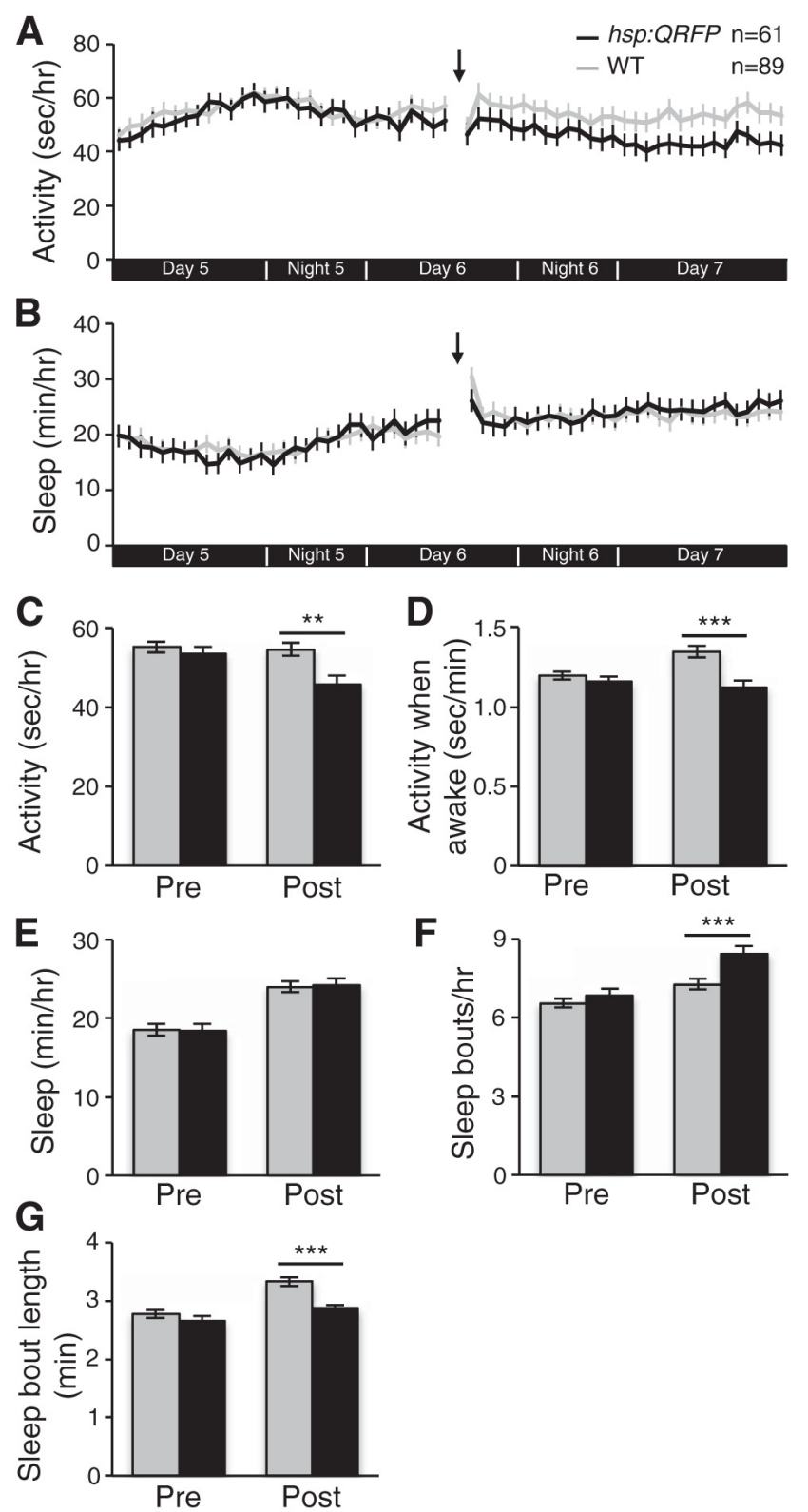

Figure 15. QRFP overexpression decreases locomotor activity in larvae raised and tested in constant dark. $\boldsymbol{A}, \boldsymbol{C}, \boldsymbol{D}$, When raised and tested in constant dark, $T g$ (hsp:QRFP) larvae (black) exhibit less locomotor activity $(\boldsymbol{A}, \boldsymbol{C})$ and less activity when awake $(\boldsymbol{D})$ than their nontransgenic WT siblings (gray) following a heat shock given during Day 6 of development (indicated by arrows and gaps in line graphs). $\boldsymbol{B}, \boldsymbol{E}-\boldsymbol{G}, \mathrm{QRFP}$ overexpression had no effect on the amount of sleep $(\boldsymbol{B}, \boldsymbol{E})$, although it did affect the number $(\boldsymbol{F})$ and length $(\boldsymbol{G})$ of sleep bouts. The $x$-axes in $\boldsymbol{A}$ and $\boldsymbol{B}$ indicate time periods that correspond to day and night in standard light/dark conditions. Line and bar graphs represent the mean \pm SEM. Bar graphs quantify values for $30 \mathrm{~h}$ pre-heat shock and post-heat shock. $n$ indicates the number of larvae analyzed. ${ }^{* *} p<0.01$, ${ }^{* * *} p<$ 0.001 for pairwise comparisons of $\operatorname{Tg}$ (hsp:QRFP) and WT larvae using Student's $t$ test.

\section{Discussion}

In this study, we investigated the role of QRFP signaling in regulating vertebrate locomotor activity and sleep using genetics in zebrafish. While mammalian sleep is usually monitored using electrophysiology, sleep can also be behaviorally defined using three criteria (Campbell and Tobler, 1984; Borbély and Tobler, 1996; Allada and Siegel, 2008). First, sleep mostly occurs during a specific period of the circadian cycle. Second, sleep is associated with an increased arousal threshold. Third, sleep is homeostatically controlled, which can be demonstrated as an increased need for sleep following sleep deprivation. Based on these criteria, rest in a variety of organisms, including zebrafish (Zhdanova et al., 2001; Prober et al., 2006; Yokogawa et al., 2007), has been shown to meet the behavioral definition of sleep. Several groups have demonstrated behavioral, anatomical, genetic, and pharmacological conservation of sleep between zebrafish and mammals, establishing zebrafish as a simple vertebrate model for sleep research (Zhdanova et al., 2001; Kaslin et al., 2004; Faraco et al., 2006; Prober et al., 2006; Renier et al., 2007; Yokogawa et al., 2007; Rihel et al., 2010; Elbaz et al., 2012; Gandhi et al., 2015; Singh et al., 2015). Using zebrafish gain-of-function and loss-offunction genetic reagents, we found that QRFP/Gpr103 signaling is both necessary and sufficient to limit locomotor activity during the day, and is necessary to maintain normal daytime sleep levels. To our knowledge, this is the first report of a neuropeptidergic signaling pathway that is required to promote sleep in a diurnal vertebrate animal.

Several studies in rodents have implicated QRFP in regulating locomotor activity, although a role in sleep has not been described. One study (Takayasu et al., 2006) reported that intracerebroventricular injection of mature QRFP peptide 43RFa in mice stimulated locomotor activity for $2-3 \mathrm{~h}$ after peptide injection. This phenotype was observed during both the light and dark periods, but was stronger during the light period, when mice are primarily asleep. A second study (do Rego et al., 2006) found that intracerebroventricular administration of $43 \mathrm{RFa}$ or $26 \mathrm{RFa}$ in mice stimulated locomotor activity for 30-60 min. In contrast, a third study (Kampe et al., 2006) found that intracerebroventricular 26RFa administration in rats had no effect on locomotor activity, and a fourth study (Moriya et al., 2006) found that chronic intracerebroventricular administration of 43RFa for $13 \mathrm{~d}$ in mice caused a small but statistically insignificant decrease in locomotor activity during the dark phase. Thus, while these studies suggest that QRFP may regulate locomotor activity in nocturnal rodents, the transient and inconsistent nature of the phenotypes makes it difficult to draw conclusions regarding the role of QRFP in regulating locomotor activity.

Our studies of QRFP/Gpr103 function in zebrafish have several advantages over previously described studies in rodents. First, we use a noninvasive heat shock-induced genetic overexpression approach, which allows for more reproducible overexpression among animals compared with intracerebroventricular injection. These injections provide more specific peptide targeting compared with heat shock-induced overexpression in zebrafish, which induces gene overexpression throughout the animal. However, the zebrafish QRFP overexpression phenotype is unlikely to be an artifact because the zebrafish qrfp and gpr103 mutants exhibit the opposite behavioral phenotype. Second, we observed gain-of-function and loss-of-function phenotypes that persisted for multiple days. In contrast, phenotypes induced by QRFP peptide injection in rodents lasted only a few hours, and are thus less robust and more subject to artifacts caused by animal handling. Third, because our study monitored the behavior of 96 zebrafish larvae simultaneously, we were able to assay many more animals than is possible in rodent experiments, which may produce more reproducible data. Fourth, rodent studies used QRFP peptides that were synthesized and modified in vitro. Because QRFP undergoes cleavage and modification in vivo, peptides synthesized in vitro might not be properly modified, which could result in reduced or abnormal function. In contrast, we overexpressed the full-length qrfp gene in zebrafish in vivo, which allows the protein to be cleaved and modified by endogenous mechanisms. As a result, QRFP that is overexpressed in zebrafish is 

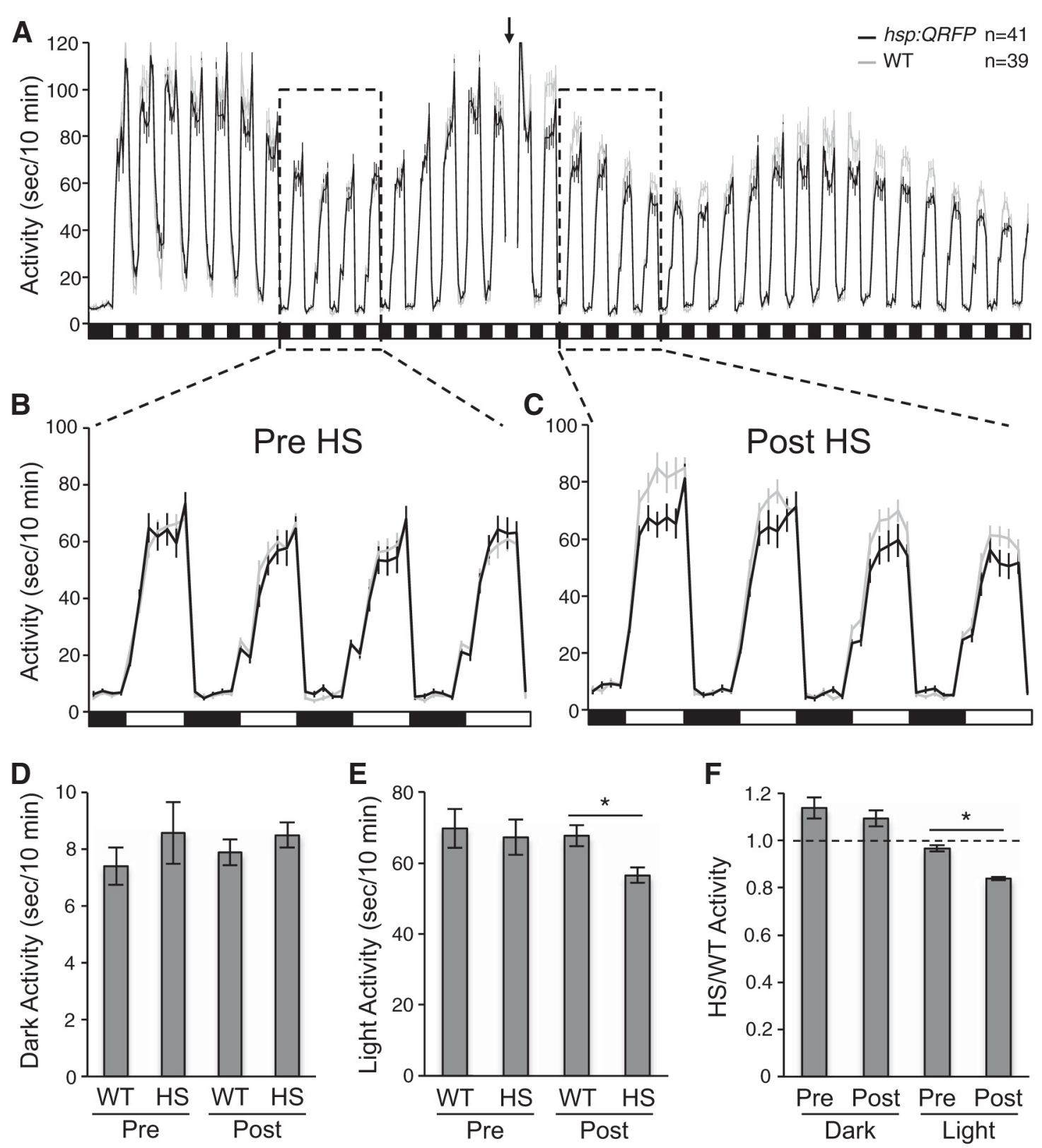

Figure 16. QRFP overexpression decreases locomotor activity in light but not in dark conditions. $A, T g(h s p: Q R F P)$ larvae (black) and their WT siblings (gray) were entrained for $4 \mathrm{~d}$ on a $14 \mathrm{~h} / 10 \mathrm{~h}$ light/dark cycle (data not shown), and were then exposed to alternating $1 \mathrm{~h}$ periods of lights on and off (indicated by white and black boxes) starting on the morning of the fifth day of development. Larvae were heat shocked during the afternoon of the sixth day of development (indicated by arrow and gap in line graph). $\boldsymbol{B}, \boldsymbol{C}$, Boxed regions before ( $\boldsymbol{B}$ ) and after ( $\boldsymbol{C}$ ) heat shock are shown at higher temporal resolution. $\boldsymbol{D}$, The average amount of locomotor activity was not significantly different between $\mathrm{Tg}(\mathrm{hsp}: \mathrm{QRFP}$ ) and WT larvae during dark periods either before or after heat shock. $\boldsymbol{E}$, The average amount of locomotor activity was not significantly different between $T g(h s p: Q R F P$ ) and WT larvae during light periods before heat shock, but $T g$ (hsp:QRFP) larvae were significantly less active than WT larvae during light periods after heat shock. $\boldsymbol{F}$, Because the amount of locomotor activity for both genotypes varied depending on the circadian time $(\boldsymbol{A})$, we also calculated the ratio of $\mathrm{Tg}$ (hsp:QRFP)/WT locomotor activity during each $1 \mathrm{~h}$ light or dark trial, and compared these ratios before and after heat shock. For dark trials, there was no significant difference after heat shock compared with before heat shock. However, for light trials there was a significant decrease after heat shock compared with before heat shock. Dashed line indicates a ratio value of 1. Line and bar graphs represent the mean \pm SEM. $n$ indicates the number of larvae analyzed. ${ }^{*} p<0.05$ for the indicated pairwise comparisons using ANOVA followed by Tukey's HSD test to correct for multiple comparisons.

more likely to be similar to naturally produced QRFP. Together, we suggest that our analysis of QRFP/Gpr103 function in zebrafish provides several advantages over rodent studies and has provided novel insights into QRFP function.

The human qrfp gene encodes a 136 aa prepropeptide that is cleaved to form the mature 26RFa and 43RFa peptides (Chartrel et al., 2011; Ukena et al., 2014). While the mammalian 26RFa peptide is well conserved in zebrafish, it is unclear whether zebrafish produce a peptide similar to mammalian $43 \mathrm{RFa}$. The ze- brafish QRFP preproprotein contains an Arg-Arg motif, as well as a Lys-Arg motif that is conserved with goldfish, which could generate N-terminal elongated peptides of 54 or 60 aa, respectively. However, these extended sequences have low homology with the mammalian peptides (Fig. $1 B$ ), so it is unclear whether these zebrafish peptides are generated in vivo. Additional studies are required to identify the mature QRFP peptides that are produced in zebrafish and to determine their functions. However, regardless of whether zebrafish produce these elongated peptides, our 
loss-of-function studies provide strong evidence that QRFP signaling is required to maintain normal daytime sleep levels.

Our findings indicate that QRFP/Gpr103 signaling regulates sleep primarily during the light phase in a diurnal animal, but this pathway may have a different role in nocturnal animals. Mice containing a targeted knockout of gpr103a exhibit defects in bone formation, but lack additional obvious phenotypes (Baribault et al., 2006), possibly due to redundant function of $g$ pr103b. Mice lacking $q r f p$ or both qrfp103a and $g p r 103 b$ will need to be tested to determine whether QRFP/Gpr103 signaling is required to regulate sleep in mammals. In particular, these mutants may reveal whether QRFP signaling regulates sleep during the light phase, when diurnal animals are primarily awake and nocturnal animals are primarily asleep. Alternatively, this pathway may be required to regulate sleep during the time when an animal is primarily awake, which corresponds to the day in diurnal animals and night in nocturnal animals. It is also possible that QRFP signaling only promotes sleep in diurnal animals, or has different functions in mammals and teleosts. If the zebrafish qrfp and gpr103 mutant phenotypes are found to be conserved in mammals, it may be useful to screen for mutations in these genes and to assay QRFP peptide levels in humans with sleep disorders.

How might QRFP/Gpr103 signaling regulate sleep? Mammalian sleep is thought to be regulated by mutual inhibition of wakeand sleep-promoting neurons, which generates a "flip-flop" switch that ensures a rapid transition between stable wake and sleep states (for review, see Saper et al., 2010; Brown et al., 2012). Several neuronal centers that are thought to promote sleep have been identified. These include neurons in the ventrolateral preoptic nucleus containing the inhibitory neurotransmitter GABA and the inhibitory peptide galanin (Sherin et al., 1996), neurons in the lateral hypothalamus containing GABA and the inhibitory peptide melanin-concentrating hormone (Konadhode et al., 2013; Tsunematsu et al., 2014), GABAergic median preoptic nucleus neurons (Suntsova et al., 2007), GABAergic neurons in the medullary parafacial zone (Anaclet et al., 2014), and somatostatin-positive GABAergic neurons in the basal forebrain (Xu et al., 2015). These neurons are thought to inhibit wakepromoting glutamatergic neurons in the parabrachial nucleus and preceruleus, glutamatergic hypocretin neurons in the lateral hypothalamus, glutamatergic and cholinergic neurons in the basal forebrain, and monoaminergic and cholinergic nuclei of the ascending arousal system, resulting in the promotion of sleep. However, lesion studies suggest that additional sleep-promoting neuronal centers are present (Lu et al., 2000; Fuller et al., 2011). Our results suggest that QRFP neurons may compose one of these sleep-promoting centers. An interesting aspect of QRFP neurons is that they are glutamatergic, and thus excitatory, in contrast to most previously described sleep-promoting neurons, which are inhibitory (Saper et al., 2010; Brown et al., 2012; Anaclet et al., 2014). This distinction suggests that QRFP neurons may interact with the flip-flop switch or other sleep regulatory mechanisms in a manner that is distinct from previously described sleep-promoting neurons. Optogenetic approaches can be used to stimulate and inhibit QRFP neurons to determine whether they are indeed sleep promoting and to test whether they interact with other neurons that are known to regulate sleep.

\section{References}

Adamantidis AR, Zhang F, Aravanis AM, Deisseroth K, de Lecea L (2007) Neural substrates of awakening probed with optogenetic control of hypocretin neurons. Nature 450:420-424. CrossRef Medline

Allada R, Siegel JM (2008) Unearthing the phylogenetic roots of sleep. Curr Biol 18:R670-R679. CrossRef Medline
Anaclet C, Ferrari L, Arrigoni E, Bass CE, Saper CB, Lu J, Fuller PM (2014) The GABAergic parafacial zone is a medullary slow wave sleep-promoting center. Nat Neurosci 17:1217-1224. CrossRef Medline

Asakawa K, Kawakami K (2009) The Tol2-mediated Gal4-UAS method for gene and enhancer trapping in zebrafish. Methods 49:275-281. CrossRef Medline

Baribault H, Danao J, Gupte J, Yang L, Sun B, Richards W, Tian H (2006) The G-protein-coupled receptor GPR103 regulates bone formation. Mol Cell Biol 26:709-717. CrossRef Medline

Bergeron SA, Hannan MC, Codore H, Fero K, Li GH, Moak Z, Yokogawa T, Burgess HA (2012) Brain selective transgene expression in zebrafish using an NRSE derived motif. Front Neural Circuits 6:110. CrossRef Medline

Borbély AA, Tobler I (1996) Sleep regulation: relation to photoperiod, sleep duration, waking activity, and torpor. Prog Brain Res 111:343-348. CrossRef Medline

Brown RE, Basheer R, McKenna JT, Strecker RE, McCarley RW (2012) Control of sleep and wakefulness. Physiol Rev 92:1087-1187. CrossRef Medline

Bruzzone F, Lectez B, Tollemer H, Leprince J, Dujardin C, Rachidi W, Chatenet D, Baroncini M, Beauvillain JC, Vallarino M, Vaudry H, Chartrel N (2006) Anatomical distribution and biochemical characterization of the novel RFamide peptide $26 \mathrm{RFa}$ in the human hypothalamus and spinal cord. J Neurochem 99:616-627. CrossRef Medline

Bruzzone F, Lectez B, Alexandre D, Jégou S, Mounien L, Tollemer H, Chatenet D, Leprince J, Vallarino M, Vaudry H, Chartrel N (2007) Distribution of 26RFa binding sites and GPR103 mRNA in the central nervous system of the rat. J Comp Neurol 503:573-591. CrossRef Medline

Campbell SS, Tobler I (1984) Animal sleep: a review of sleep duration across phylogeny. Neurosci Biobehav Rev 8:269-300. CrossRef Medline

Chartrel N, Dujardin C, Anouar Y, Leprince J, Decker A, Clerens S, Do-Régo JC, Vandesande F, Llorens-Cortes C, Costentin J, Beauvillain JC, Vaudry $\mathrm{H}$ (2003) Identification of 26RFa, a hypothalamic neuropeptide of the RFamide peptide family with orexigenic activity. Proc Natl Acad Sci U S A 100:15247-15252. CrossRef Medline

Chartrel N, Alonzeau J, Alexandre D, Jeandel L, Alvear-Perez R, Leprince J, Boutin J, Vaudry H, Anouar Y, Llorens-Cortes C (2011) The RFamide neuropeptide $26 \mathrm{RFa}$ and its role in the control of neuroendocrine functions. Front Neuroendocrinol 32:387-397. CrossRef Medline

Chemelli RM, Willie JT, Sinton CM, Elmquist JK, Scammell T, Lee C, Richardson JA, Williams SC, Xiong Y, Kisanuki Y, Fitch TE, Nakazato M, Hammer RE, Saper CB, Yanagisawa M (1999) Narcolepsy in orexin knockout mice: molecular genetics of sleep regulation. Cell 98:437-451. CrossRef Medline

Chen S, Oikonomou G, Chiu CN, Niles BJ, Liu J, Lee DA, Antoshechkin I, Prober DA (2013) A large-scale in vivo analysis reveals that TALENs are significantly more mutagenic than ZFNs generated using contextdependent assembly. Nucleic Acids Res 41:2769-2778. CrossRef Medline

de Lecea L, Kilduff TS, Peyron C, Gao X, Foye PE, Danielson PE, Fukuhara C, Battenberg EL, Gautvik VT, Bartlett FS 2nd, Frankel WN, van den Pol AN, Bloom FE, Gautvik KM, Sutcliffe JG (1998) The hypocretins: hypothalamus-specific peptides with neuroexcitatory activity. Proc Natl Acad Sci U S A 95:322-327. CrossRef Medline

do Rego JC, Leprince J, Chartrel N, Vaudry H, Costentin J (2006) Behavioral effects of 26RFamide and related peptides. Peptides 27:2715-2721. CrossRef Medline

Eaton JL, Holmqvist B, Glasgow E (2008) Ontogeny of vasotocinexpressing cells in zebrafish: selective requirement for the transcriptional regulators orthopedia and single-minded 1 in the preoptic area. Dev Dyn 237:995-1005. CrossRef Medline

Elbaz I, Yelin-Bekerman L, Nicenboim J, Vatine G, Appelbaum L (2012) Genetic ablation of hypocretin neurons alters behavioral state transitions in zebrafish. J Neurosci 32:12961-12972. CrossRef Medline

Faraco JH, Appelbaum L, Marin W, Gaus SE, Mourrain P, Mignot E (2006) Regulation of hypocretin (orexin) expression in embryonic zebrafish. J Biol Chem 281:29753-29761. CrossRef Medline

Foley JE, Maeder ML, Pearlberg J, Joung JK, Peterson RT, Yeh JR (2009) Targeted mutagenesis in zebrafish using customized zinc-finger nucleases. Nat Protoc 4:1855-1867. CrossRef Medline

Fukusumi S, Yoshida H, Fujii R, Maruyama M, Komatsu H, Habata Y, Shintani Y, Hinuma S, Fujino M (2003) A new peptidic ligand and its recep- 
tor regulating adrenal function in rats. J Biol Chem 278:46387-46395. CrossRef Medline

Fuller PM, Sherman D, Pedersen NP, Saper CB, Lu J (2011) Reassessment of the structural basis of the ascending arousal system. J Comp Neurol 519: 933-956. CrossRef Medline

Gandhi AV, Mosser EA, Oikonomou G, Prober DA (2015) Melatonin is required for the circadian regulation of sleep. Neuron 85:1193-1199. CrossRef Medline

Guo S, Brush J, Teraoka H, Goddard A, Wilson SW, Mullins MC, Rosenthal A (1999) Development of noradrenergic neurons in the zebrafish hindbrain requires BMP, FGF8, and the homeodomain protein soulless/ Phox2a. Neuron 24:555-566. CrossRef Medline

Halloran MC, Sato-Maeda M, Warren JT, Su F, Lele Z, Krone PH, Kuwada JY, Shoji W (2000) Laser-induced gene expression in specific cells of transgenic zebrafish. Development 127:1953-1960. Medline

Higashijima S, Mandel G, Fetcho JR (2004) Distribution of prospective glutamatergic, glycinergic, and GABAergic neurons in embryonic and larval zebrafish. J Comp Neurol 480:1-18. CrossRef Medline

Hurd MW, Cahill GM (2002) Entraining signals initiate behavioral circadian rhythmicity in larval zebrafish. J Biol Rhythms 17:307-314. CrossRef Medline

Isken O, Maquat LE (2007) Quality control of eukaryotic mRNA: safeguarding cells from abnormal mRNA function. Genes Dev 21:1833-1856. CrossRef Medline

Jiang Y, Luo L, Gustafson EL, Yadav D, Laverty M, Murgolo N, Vassileva G, Zeng M, Laz TM, Behan J, Qiu P, Wang L, Wang S, Bayne M, Greene J, Monsma F Jr, Zhang FL (2003) Identification and characterization of a novel RF-amide peptide ligand for orphan G-protein-coupled receptor SP9155. J Biol Chem 278:27652-27657. CrossRef Medline

Kampe J, Wiedmer P, Pfluger PT, Castaneda TR, Burget L, Mondala H, Kerr J, Liaw C, Oldfield BJ, Tschöp MH, Bagnol D (2006) Effect of central administration of $\mathrm{QRFP}(26)$ peptide on energy balance and characterization of a second QRFP receptor in rat. Brain Res 1119:133-149. CrossRef Medline

Kaneko M, Cahill GM (2005) Light-dependent development of circadian gene expression in transgenic zebrafish. PLoS Biol 3:e34. CrossRef Medline

Kaslin J, Nystedt JM, Ostergård M, Peitsaro N, Panula P (2004) The orexin/ hypocretin system in zebrafish is connected to the aminergic and cholinergic systems. J Neurosci 24:2678-2689. CrossRef Medline

Konadhode RR, Pelluru D, Blanco-Centurion C, Zayachkivsky A, Liu M, Uhde T, Glen WB Jr, van den Pol AN, Mulholland PJ, Shiromani PJ (2013) Optogenetic stimulation of MCH neurons increases sleep. J Neurosci 33:10257-10263. CrossRef Medline

Larhammar D, Xu B, Bergqvist CA (2014) Unexpected multiplicity of QRFP receptors in early vertebrate evolution. Front Neurosci 8:337. CrossRef Medline

Lee DK, Nguyen T, Lynch KR, Cheng R, Vanti WB, Arkhitko O, Lewis T, Evans JF, George SR, O'Dowd BF (2001) Discovery and mapping of ten novel G protein-coupled receptor genes. Gene 275:83-91. CrossRef Medline

Lin L, Faraco J, Li R, Kadotani H, Rogers W, Lin X, Qiu X, de Jong PJ, Nishino S, Mignot E (1999) The sleep disorder canine narcolepsy is caused by a mutation in the hypocretin (orexin) receptor 2 gene. Cell 98:365-376. CrossRef Medline

Liu J, Merkle FT, Gandhi AV, Gagnon JA, Woods IG, Chiu CN, Shimogori T, Schier AF, Prober DA (2015) Evolutionarily conserved regulation of hypocretin neuron specification by Lhx9. Development 142:1113-1124. CrossRef Medline

Liu Y, Zhang Y, Li S, Huang W, Liu X, Lu D, Meng Z, Lin H (2009) Molecular cloning and functional characterization of the first non-mammalian 26RFa/QRFP orthologue in Goldfish, Carassius auratus. Mol Cell Endocrinol 303:82-90. CrossRef Medline

Livak KJ, Schmittgen TD (2001) Analysis of relative gene expression data using real-time quantitative PCR and the 2(-Delta Delta C(T)) method. Methods 25:402-408. CrossRef Medline

Lu J, Greco MA, Shiromani P, Saper CB (2000) Effect of lesions of the ventrolateral preoptic nucleus on NREM and REM sleep. J Neurosci 20: 3830-3842. Medline

Moriya R, Sano H, Umeda T, Ito M, Takahashi Y, Matsuda M, Ishihara A, Kanatani A, Iwaasa H (2006) RFamide peptide QRFP43 causes obesity with hyperphagia and reduced thermogenesis in mice. Endocrinology 147:2916-2922. CrossRef Medline

Navarro VM, Fernández-Fernández R, Nogueiras R, Vigo E, Tovar S, Chartrel N, Le Marec O, Leprince J, Aguilar E, Pinilla L, Dieguez C, Vaudry H, Tena-Sempere M (2006) Novel role of 26RFa, a hypothalamic RFamide orexigenic peptide, as putative regulator of the gonadotropic axis. J Physiol 573:237-249. CrossRef Medline

Pan YA, Freundlich T, Weissman TA, Schoppik D, Wang XC, Zimmerman S, Ciruna B, Sanes JR, Lichtman JW, Schier AF (2013) Zebrabow: multispectral cell labeling for cell tracing and lineage analysis in zebrafish. Development 140:2835-2846. CrossRef Medline

Peyron C, Faraco J, Rogers W, Ripley B, Overeem S, Charnay Y, Nevsimalova S, Aldrich M, Reynolds D, Albin R, Li R, Hungs M, Pedrazzoli M, Padigaru M, Kucherlapati M, Fan J, Maki R, Lammers GJ, Bouras C, Kucherlapati R, et al. (2000) A mutation in a case of early onset narcolepsy and a generalized absence of hypocretin peptides in human narcoleptic brains. Nat Med 6:991-997. CrossRef Medline

Prober DA, Rihel J, Onah AA, Sung RJ, Schier AF (2006) Hypocretin/orexin overexpression induces an insomnia-like phenotype in zebrafish. J Neurosci 26:13400-13410. CrossRef Medline

Renier C, Faraco JH, Bourgin P, Motley T, Bonaventure P, Rosa F, Mignot E (2007) Genomic and functional conservation of sedative-hypnotic targets in the zebrafish. Pharmacogenet Genomics 17:237-253. CrossRef Medline

Rihel J, Prober DA, Arvanites A, Lam K, Zimmerman S, Jang S, Haggarty SJ, Kokel D, Rubin LL, Peterson RT, Schier AF (2010) Zebrafish behavioral profiling links drugs to biological targets and rest/wake regulation. Science 327:348-351. CrossRef Medline

Sander JD, Cade L, Khayter C, Reyon D, Peterson RT, Joung JK, Yeh JR (2011) Targeted gene disruption in somatic zebrafish cells using engineered TALENs. Nat Biotechnol 29:697-698. CrossRef Medline

Sandvik GK, Hodne K, Haug TM, Okubo K, Weltzien FA (2014) RFamide peptides in early vertebrate development. Front Endocrinol 5:203. CrossRef Medline

Saper CB, Fuller PM, Pedersen NP, Lu J, Scammell TE (2010) Sleep state switching. Neuron 68:1023-1042. CrossRef Medline

Sherin JE, Shiromani PJ, McCarley RW, Saper CB (1996) Activation of ventrolateral preoptic neurons during sleep. Science 271:216-219. CrossRef Medline

Singh C, Oikonomou G, Prober DA (2015) Norepinephrine is required to promote wakefulness and for hypocretin-induced arousal in zebrafish. Elife 4:e07000. CrossRef Medline

Suntsova N, Guzman-Marin R, Kumar S, Alam MN, Szymusiak R, McGinty D (2007) The median preoptic nucleus reciprocally modulates activity of arousal-related and sleep-related neurons in the perifornical lateral hypothalamus. J Neurosci 27:1616-1630. CrossRef Medline

Takayasu S, Sakurai T, Iwasaki S, Teranishi H, Yamanaka A, Williams SC, Iguchi H, Kawasawa YI, Ikeda Y, Sakakibara I, Ohno K, Ioka RX, Murakami S, Dohmae N, Xie J, Suda T, Motoike T, Ohuchi T, Yanagisawa M, Sakai J (2006) A neuropeptide ligand of the G protein-coupled receptor GPR103 regulates feeding, behavioral arousal, and blood pressure in mice. Proc Natl Acad Sci U S A 103:7438-7443. CrossRef Medline

Thermes V, Grabher C, Ristoratore F, Bourrat F, Choulika A, Wittbrodt J, Joly JS (2002) I-SceI meganuclease mediates highly efficient transgenesis in fish. Mech Dev 118:91-98. CrossRef Medline

Thisse C, Thisse B (2008) High-resolution in situ hybridization to wholemount zebrafish embryos. Nat Protoc 3:59-69. CrossRef Medline

Tobari Y, Iijima N, Tsunekawa K, Osugi T, Haraguchi S, Ubuka T, Ukena K, Okanoya K, Tsutsui K, Ozawa H (2011) Identification, localisation and functional implication of $26 \mathrm{RFa}$ orthologue peptide in the brain of zebra finch (Taeniopygia guttata). J Neuroendocrinol 23:791-803. CrossRef Medline

Tsunematsu T, Ueno T, Tabuchi S, Inutsuka A, Tanaka KF, Hasuwa $\mathrm{H}$, Kilduff TS, Terao A, Yamanaka A (2014) Optogenetic manipulation of activity and temporally controlled cell-specific ablation reveal a role for $\mathrm{MCH}$ neurons in sleep/wake regulation. J Neurosci 34:6896-6909. CrossRef Medline

Ukena K, Tachibana T, Iwakoshi-Ukena E, Saito Y, Minakata H, Kawaguchi R, Osugi T, Tobari Y, Leprince J, Vaudry H, Tsutsui K (2010) Identification, localization, and function of a novel avian hypothalamic neuropeptide, $26 \mathrm{RF}$, and its cognate receptor, $\mathrm{G}$ protein-coupled receptor-103. Endocrinology 151:2255-2264. CrossRef Medline 
Ukena K, Osugi T, Leprince J, Vaudry H, Tsutsui K (2014) Molecular evolution of GPCRs: 26Rfa/GPR103. J Mol Endocrinol 52:T119-T131. CrossRef Medline

Unger JL, Glasgow E (2003) Expression of isotocin-neurophysin mRNA in developing zebrafish. Gene Expr Patterns 3:105-108. CrossRef Medline

van den Pol AN (2012) Neuropeptide transmission in brain circuits. Neuron 76:98-115. CrossRef Medline

Verret L, Goutagny R, Fort P, Cagnon L, Salvert D, Léger L, Boissard R, Salin P, Peyron C, Luppi PH (2003) A role of melanin-concentrating hormone producing neurons in the central regulation of paradoxical sleep. BMC Neurosci 4:19. CrossRef Medline

Westerfield M (2000) The zebrafish book. A guide for the laboratory use of zebrafish (Danio rerio), Ed 4. Eugene, OR: University of Oregon.

Willie JT, Sinton CM, Maratos-Flier E, Yanagisawa M (2008) Abnormal response of melanin-concentrating hormone deficient mice to fasting: hyperactivity and rapid eye movement sleep suppression. Neuroscience 156:819-829. CrossRef Medline

Wolf A, Ryu S (2013) Specification of posterior hypothalamic neurons requires coordinated activities of Fezf2, Otp, Simla and Foxb1.2. Development 140:1762-1773. CrossRef Medline
Xie X, Mathias JR, Smith MA, Walker SL, Teng Y, Distel M, Köster RW, Sirotkin HI, Saxena MT, Mumm JS (2013) Silencer-delimited transgenesis: NRSE/RE1 sequences promote neural-specific transgene expression in a NRSF/REST-dependent manner. BMC Biol 10:93. CrossRef Medline

Xu M, Chung S, Zhang S, Zhong P, Ma C, Chang WC, Weissbourd B, Sakai N, Luo L, Nishino S, Dan Y (2015) Basal forebrain circuit for sleep-wake control. Nat Neurosci 18:1641-1647. CrossRef Medline

Yang B, Treweek JB, Kulkarni RP, Deverman BE, Chen CK, Lubeck E, Shah S, Cai L, Gradinaru V (2014) Single-cell phenotyping within transparent intact tissue through whole-body clearing. Cell 158:945-958. CrossRef Medline

Yokogawa T, Marin W, Faraco J, Pézeron G, Appelbaum L, Zhang J, Rosa F, Mourrain P, Mignot E (2007) Characterization of sleep in zebrafish and insomnia in hypocretin receptor mutants. PLoS Biol 5:e277. CrossRef Medline

Zhdanova IV, Wang SY, Leclair OU, Danilova NP (2001) Melatonin promotes sleep-like state in zebrafish. Brain Res 903:263-268. CrossRef Medline 